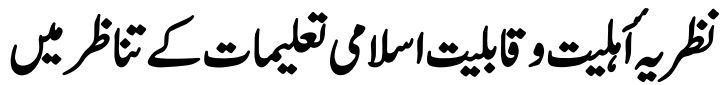

\section{The Concept of Eligibility and Competence in the Light of Islamic Teachings}

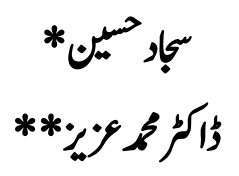

\begin{abstract}
Holy Prophet Muhammad (SAW) has practically guided the Muslims in all spheres of life including faith, jurisprudence, economics, politics and social circles. Muslims' ruled the world as long as they followed the Prophet and the Islamic teachings. As soon as they started ignoring the rules of Shari'ah, they fell into a political failure and economic deprivation. Leadership is such an important aspect in which lies the secret of national, political and social development. Leadership is given such importance in Islam that Prophet (SAW) has given special instructions about the eligibility to be the leader of Muslim society. According to Islamic Jurisprudence and the teachings of the Holy Prophet (SAW), leadership can only be given to the eligible and efficient figures. If authority and control is given to some ineligible or incapable people, it is not only unsuitable but a cruelty. Muslim Ummah in general and the public of Pakistan in particular had never so intensely desired for a noble leadership possessing high qualities as they need it today. Pakistani nation has reached the verge of chaos and destruction which is leading to fatal and horrible consequences. The ideology of standard and capability has clearly been interpreted in Qur'an and Sunnah. This is further supported by the practices of the Muslims in the past. This research has focused on gathering the data about ideology of standard and eligibility for the selection/election of individuals according to the Seerah of the Prophet (SAW).
\end{abstract}

Key Words: Standard, Eligibility, Leadership, Qualities, Sunnah, Political

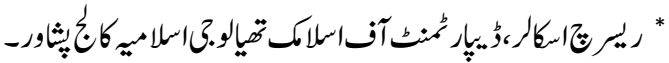

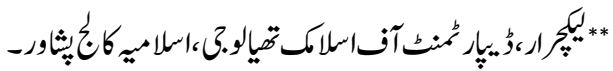




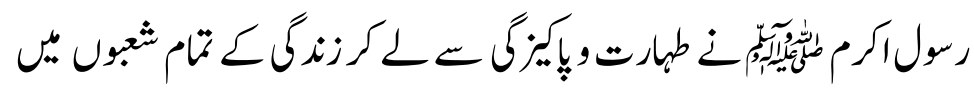

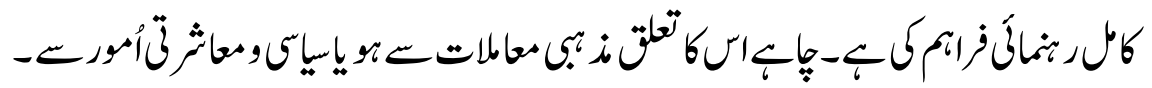

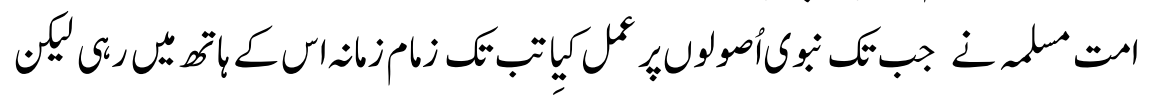

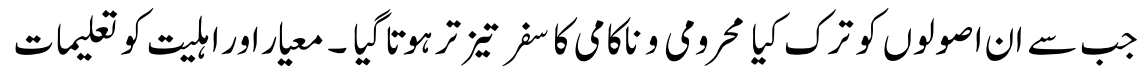

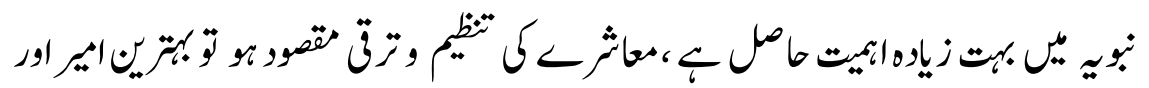

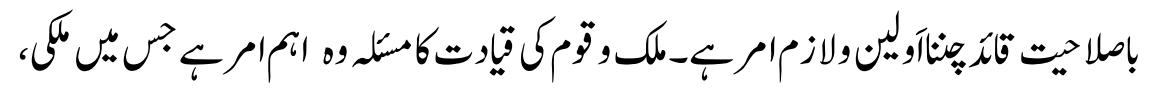

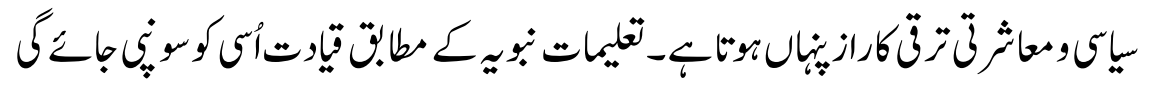

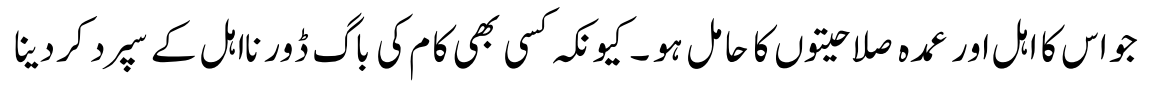

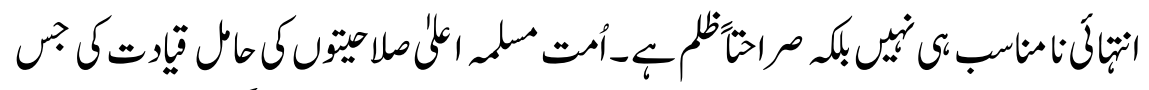

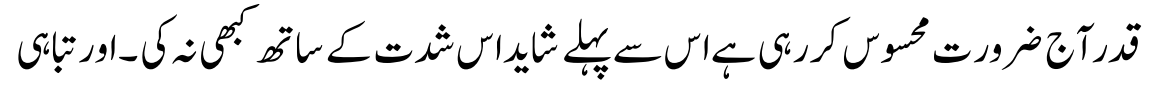

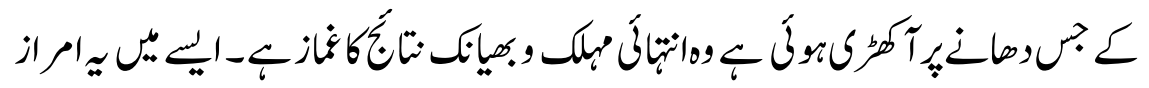

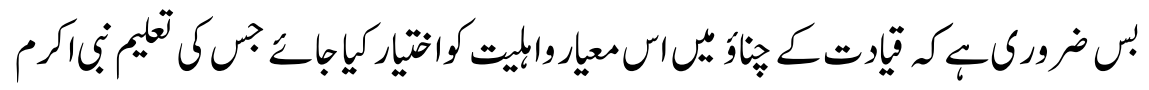

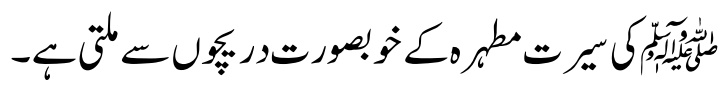

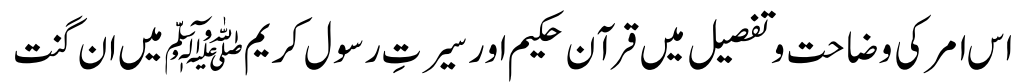

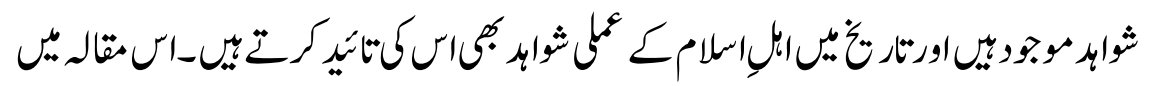

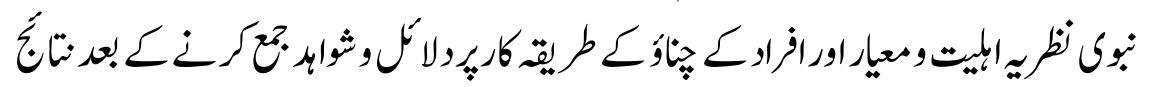

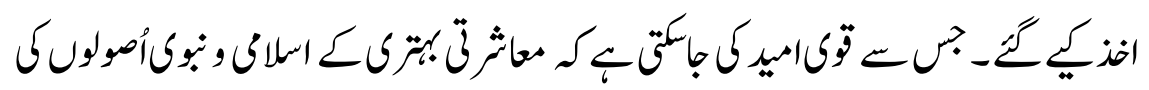

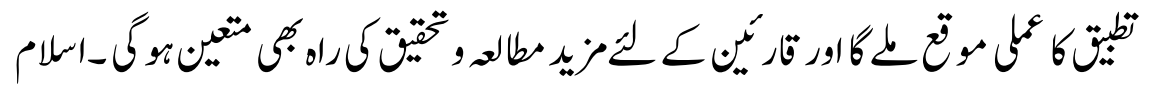

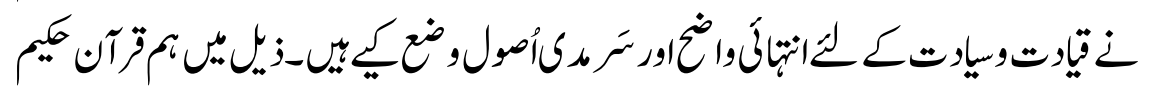

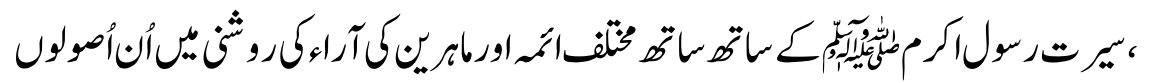
كامطالدكريك- 


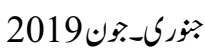

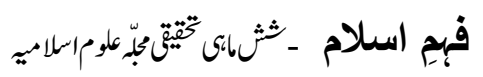

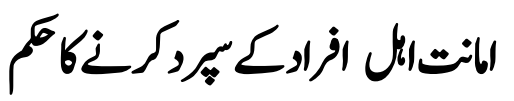

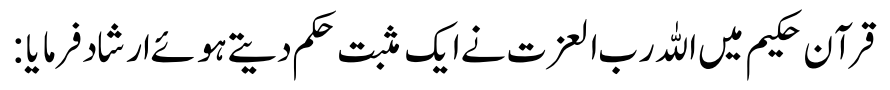

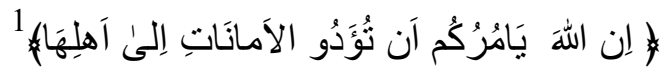

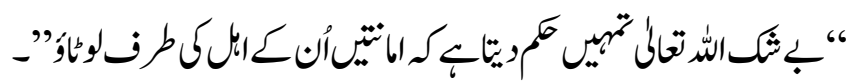

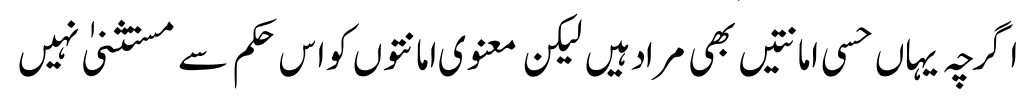

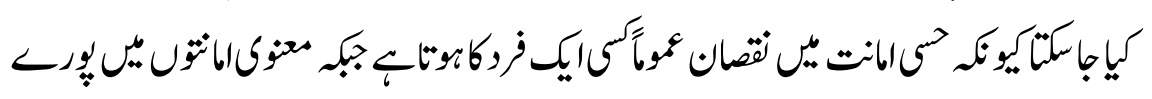

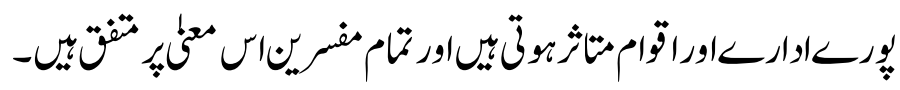

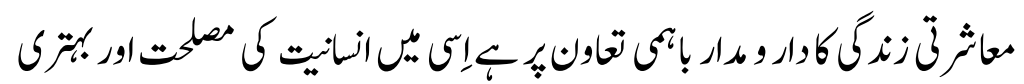

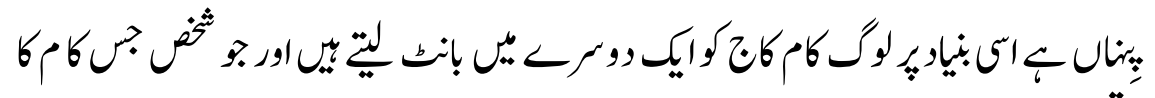

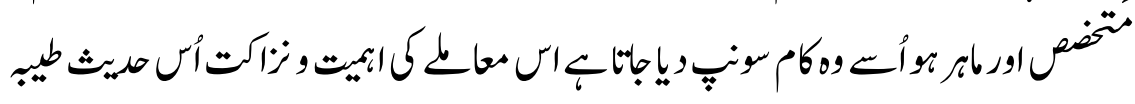

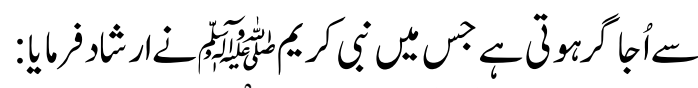

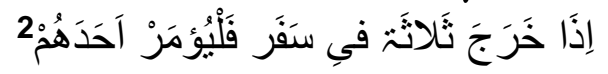

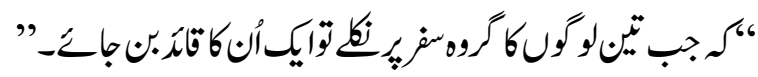

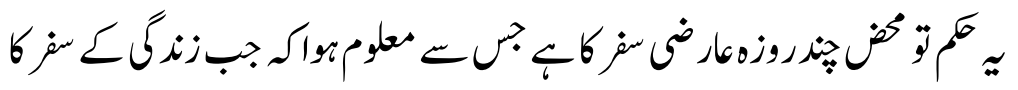

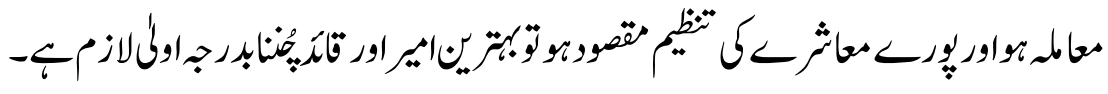

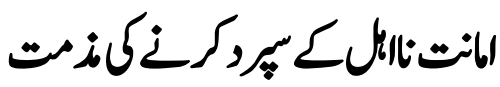

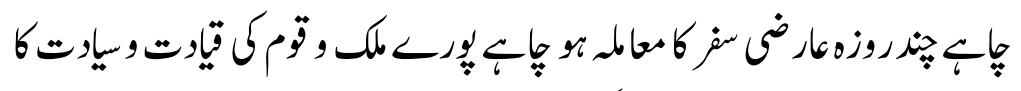

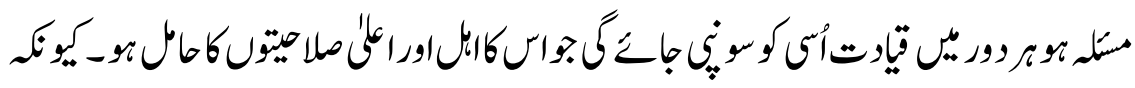

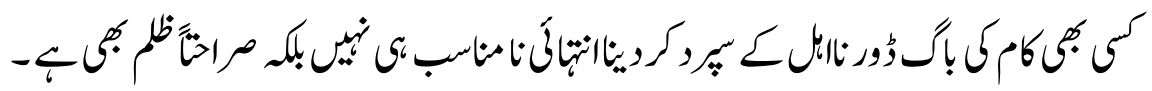

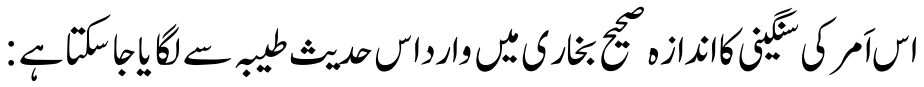

65 


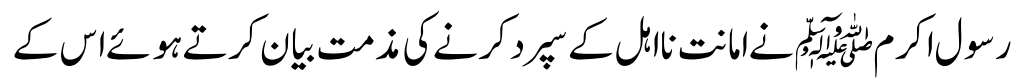

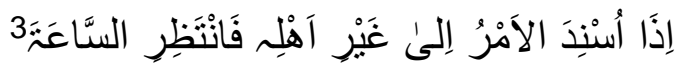

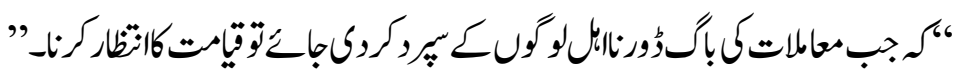

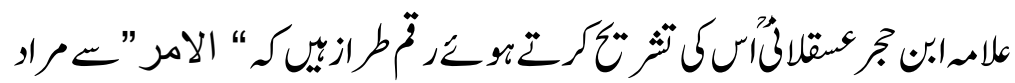

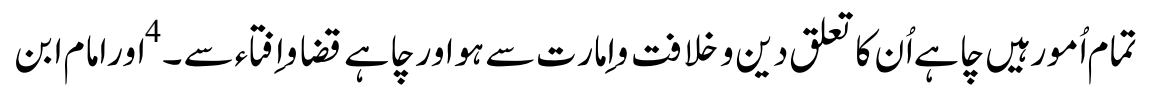

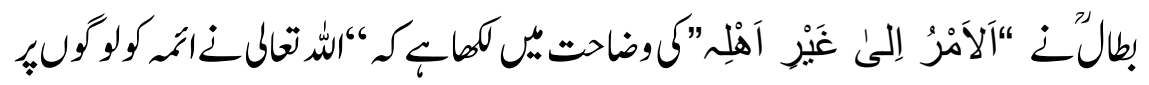

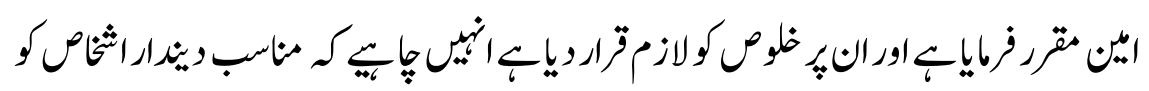

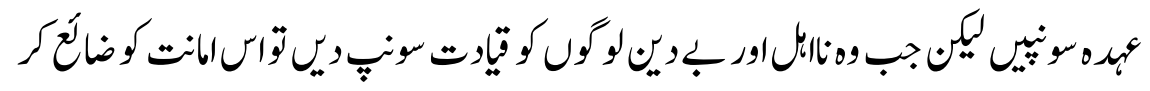

$$
5 \text {-" }
$$

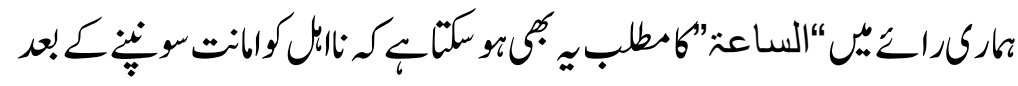

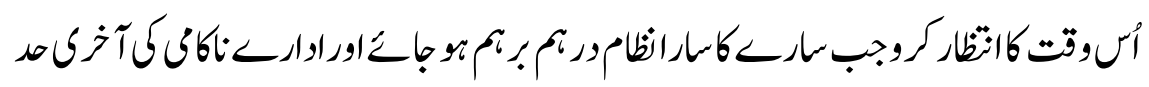

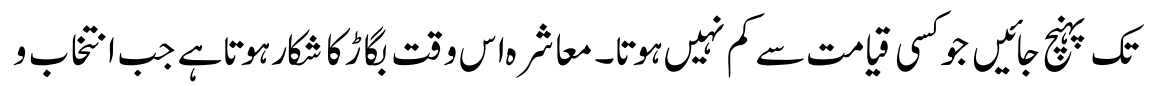

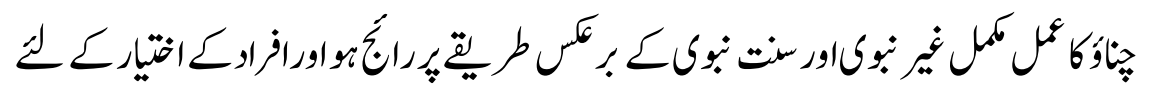

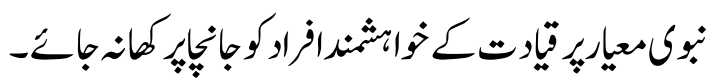

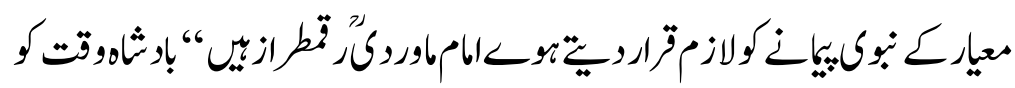

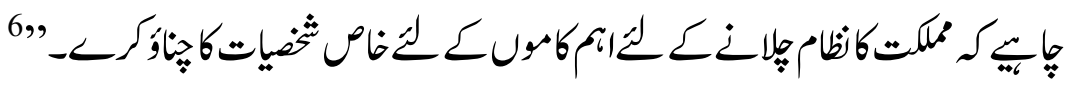

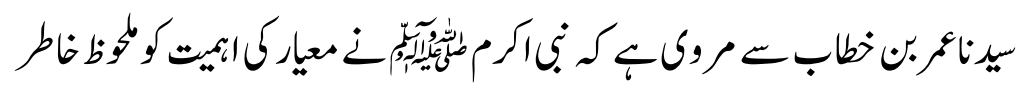

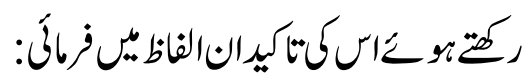

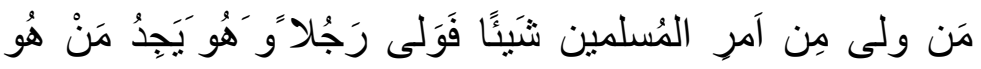

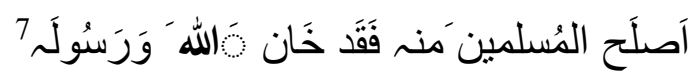




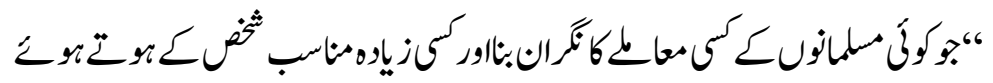

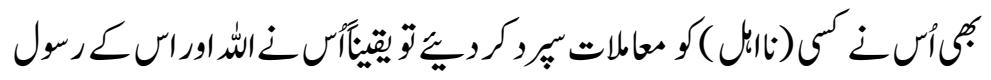

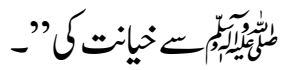

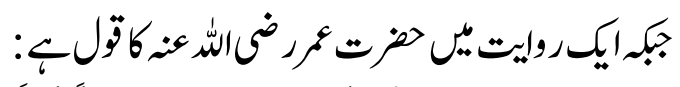

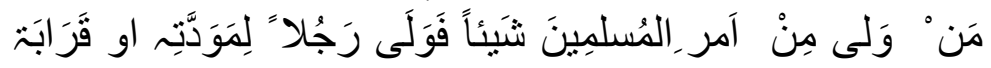

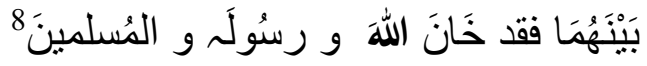

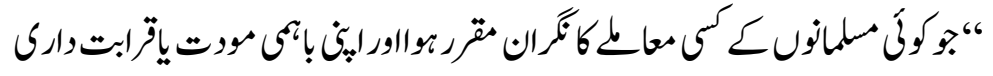

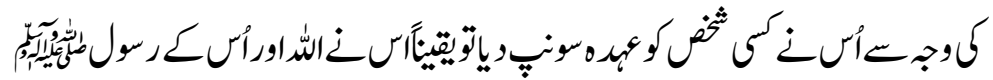

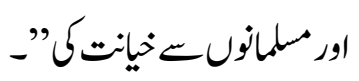

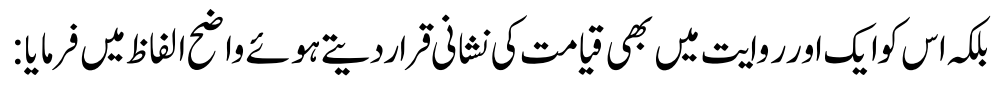

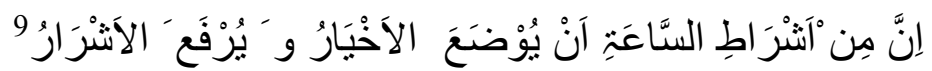

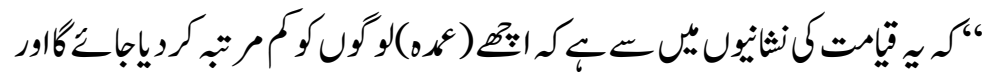

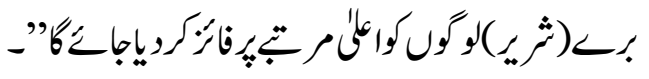

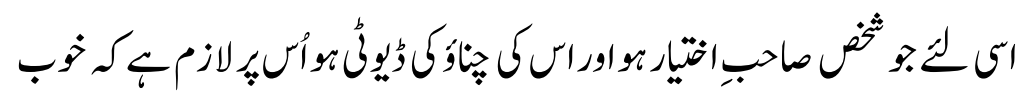

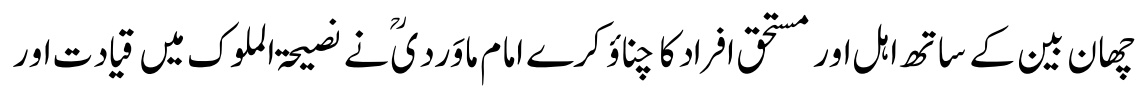

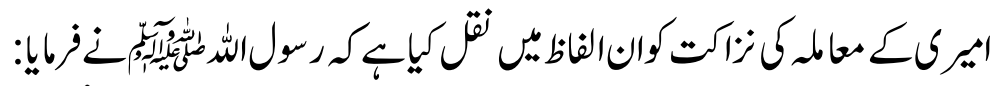

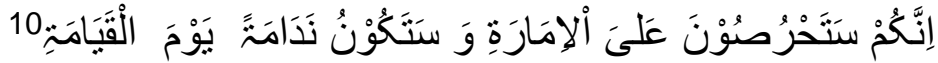

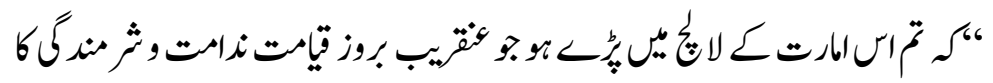

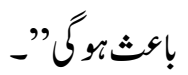


جزري_:ون2019

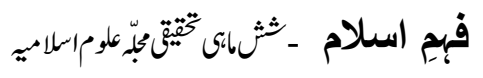

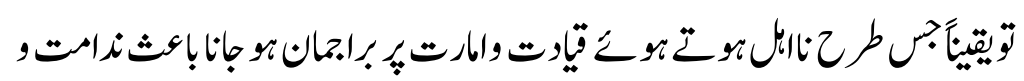

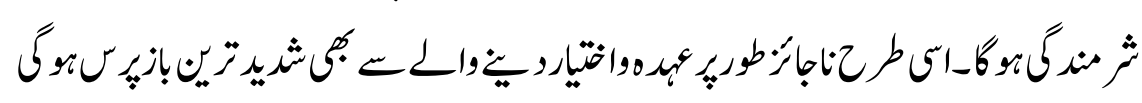

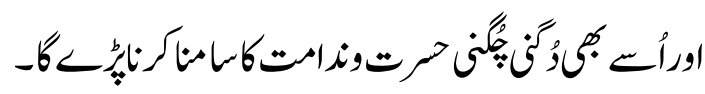

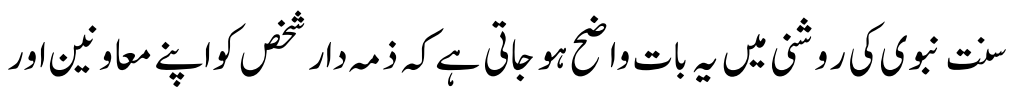

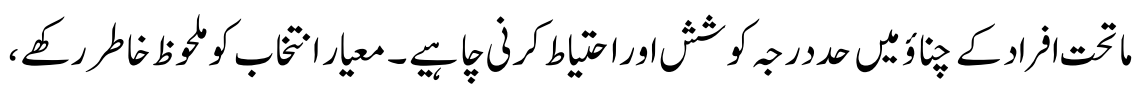

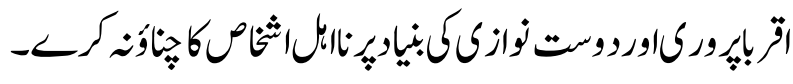

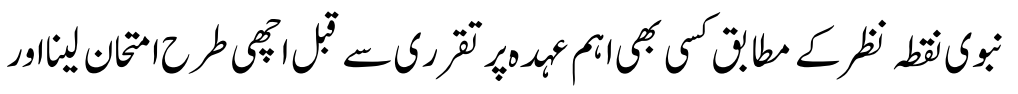

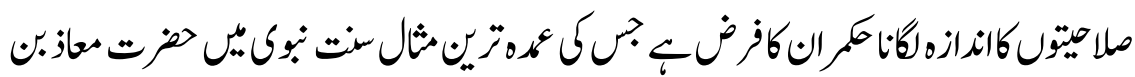

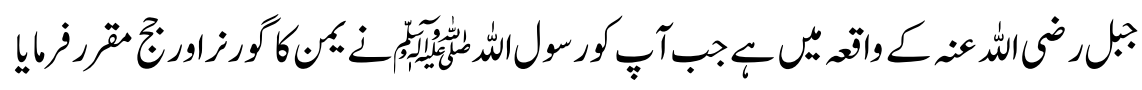

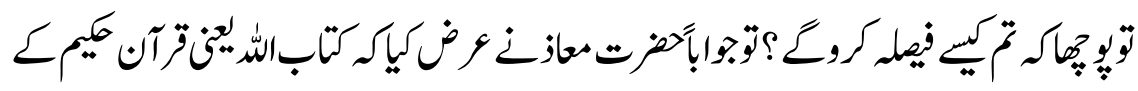

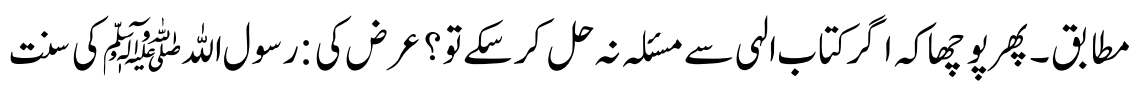

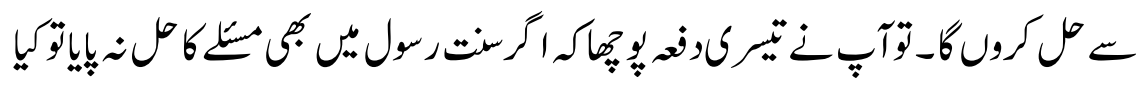

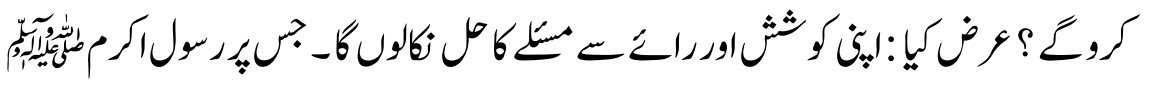

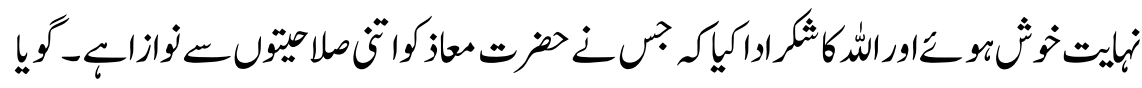

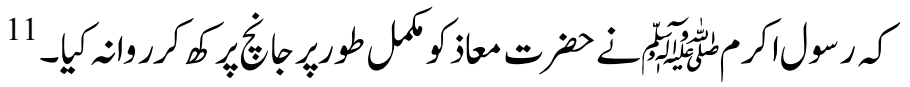

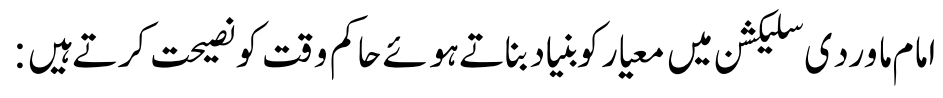

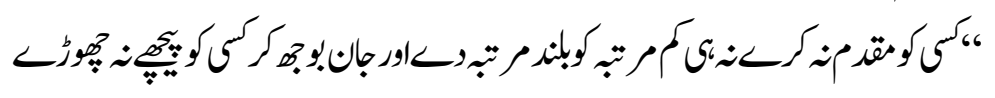

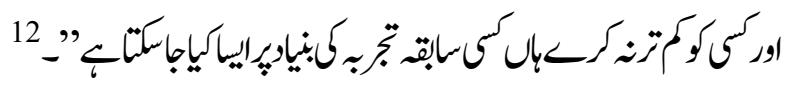

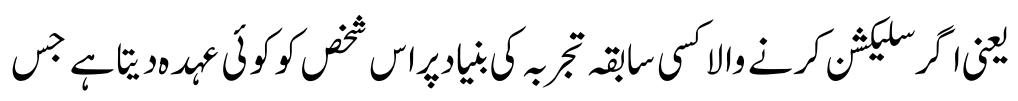

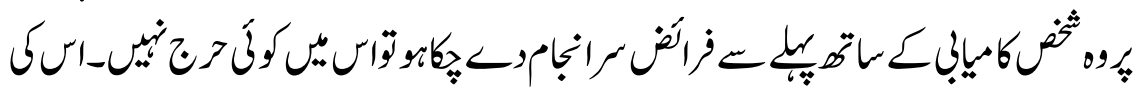

68 
جزرك-بون2019

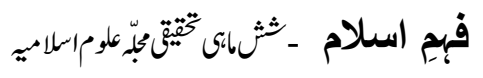

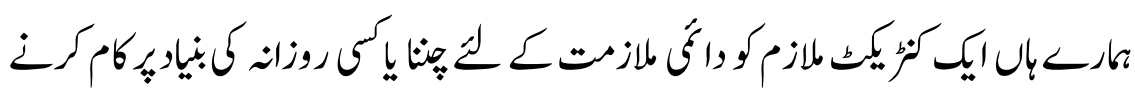

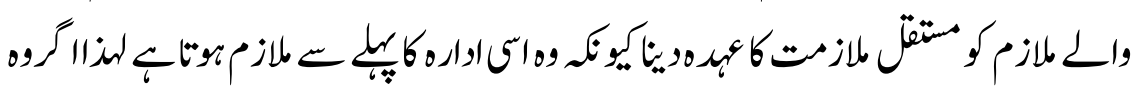

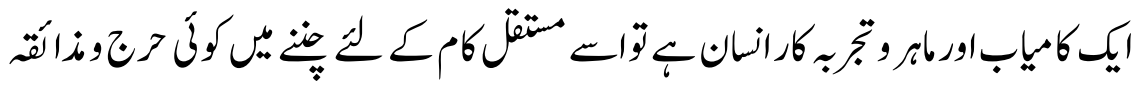

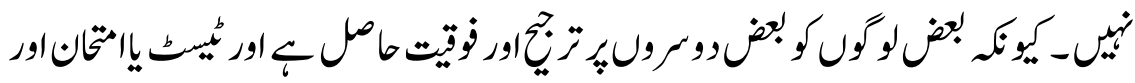

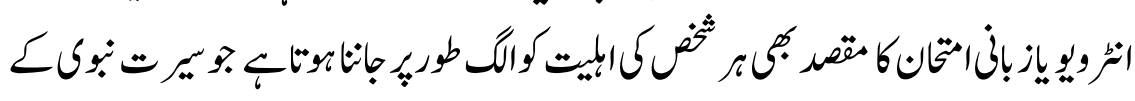

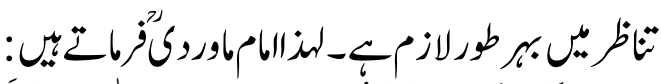

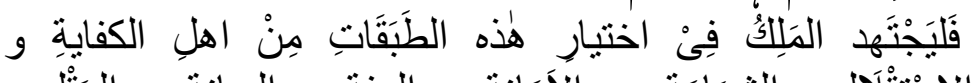

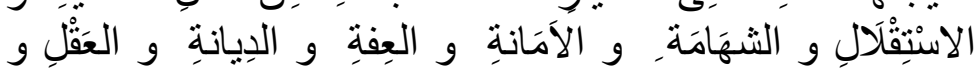

الإصَالةِ

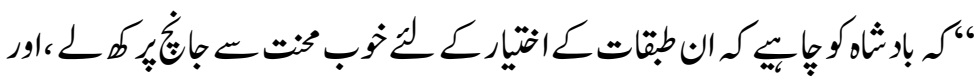

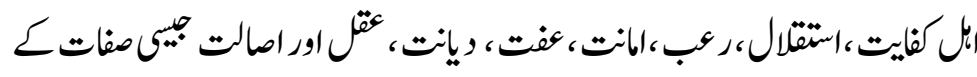

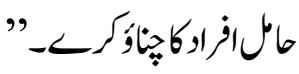

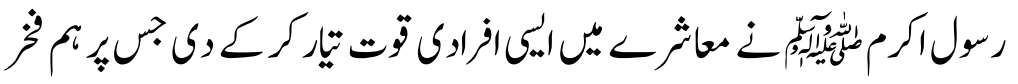

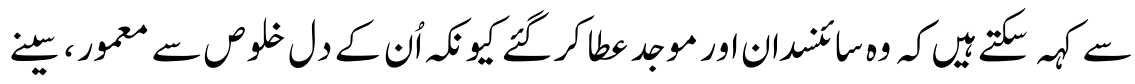

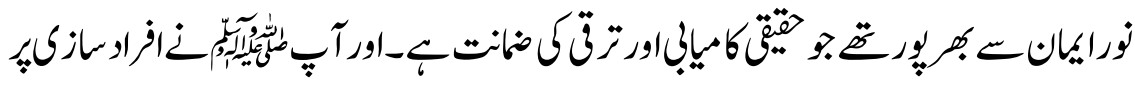

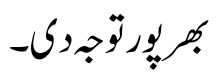

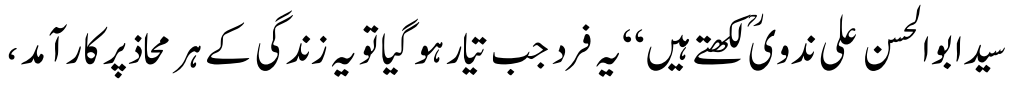

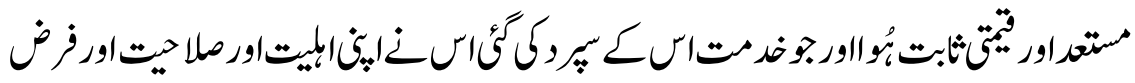

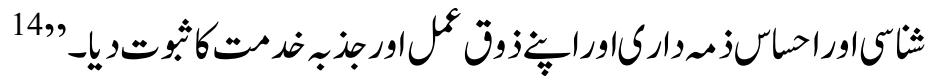

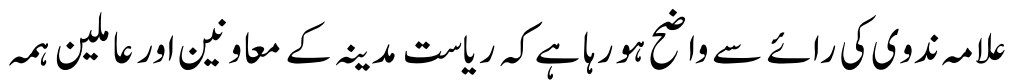

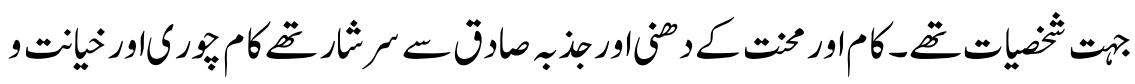

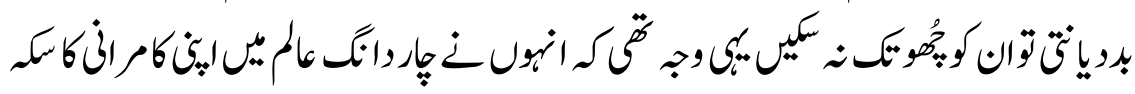

69 


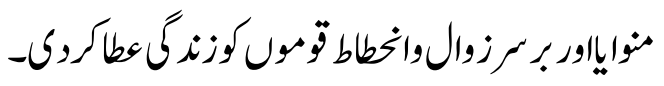

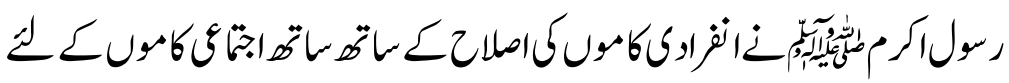

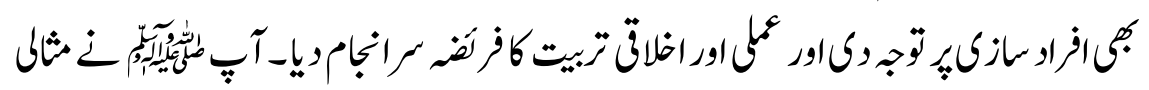

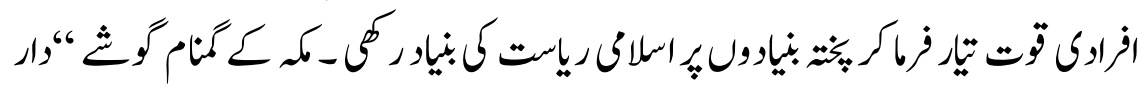

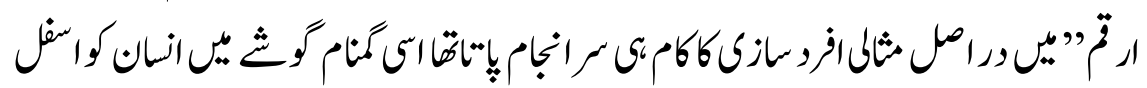

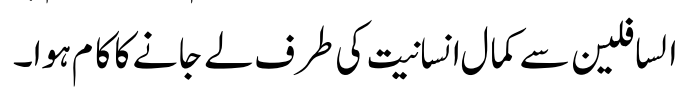

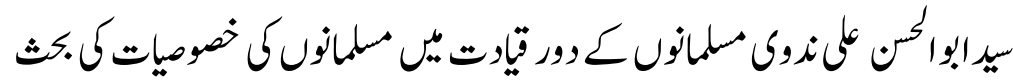

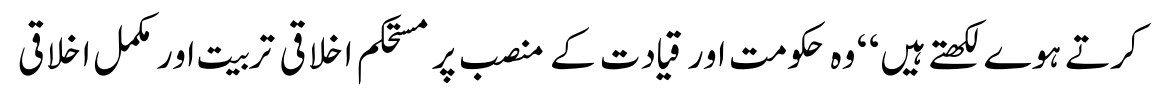

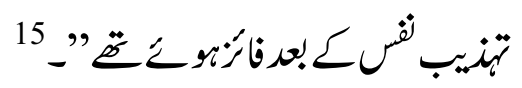

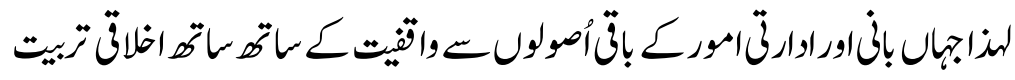

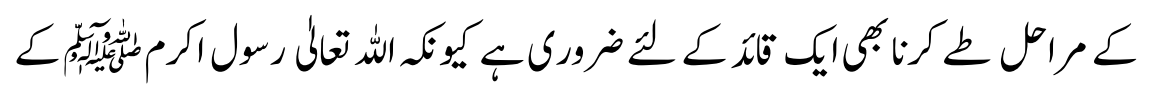

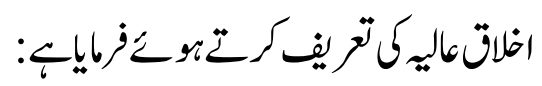

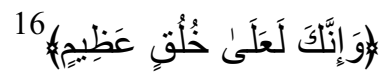

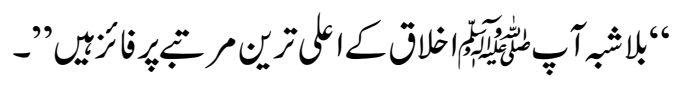

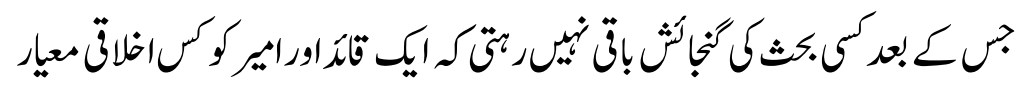

يتبوناجإِي -

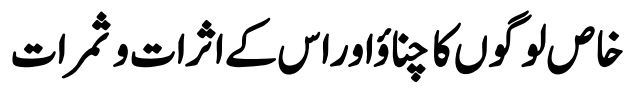

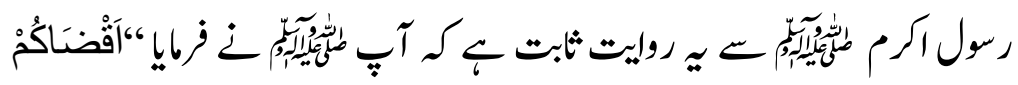

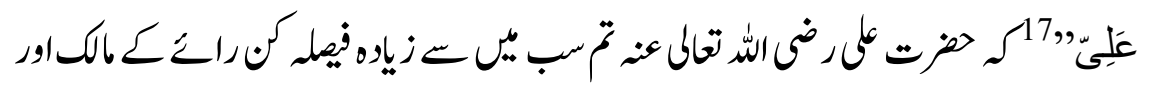
فيمل كر نكملاديت عالاباليّ- 


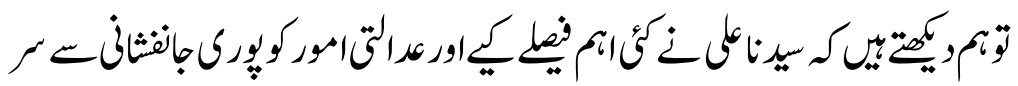

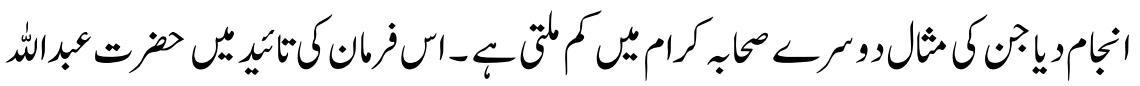

ابن مسوروزاتيكي

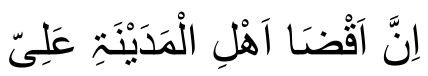

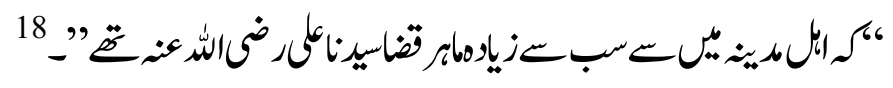

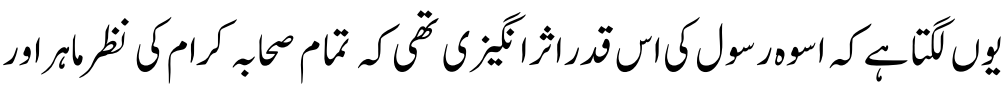

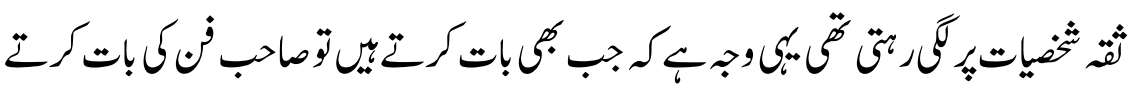

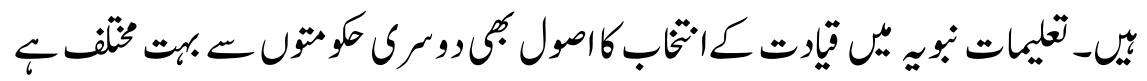

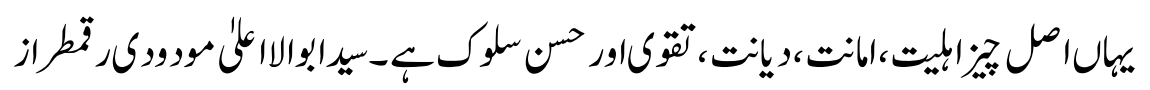

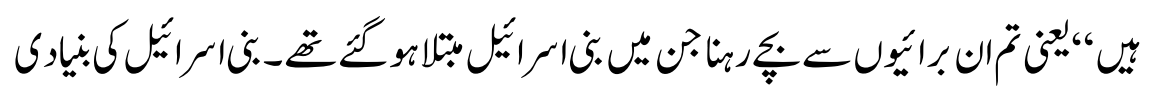

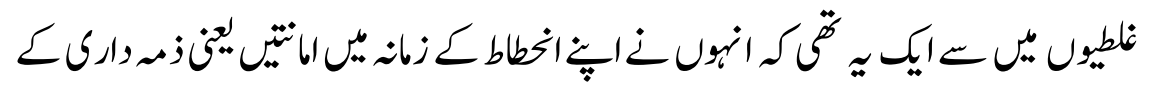

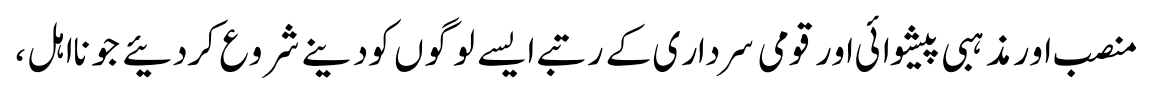

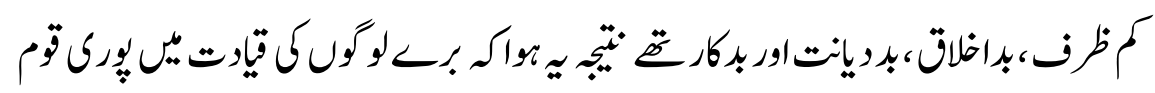

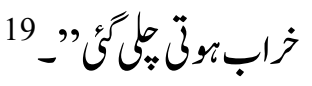

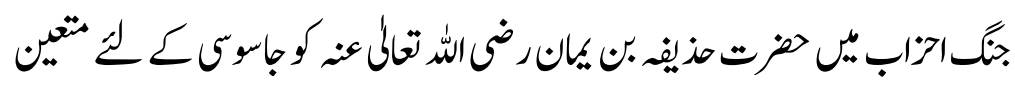

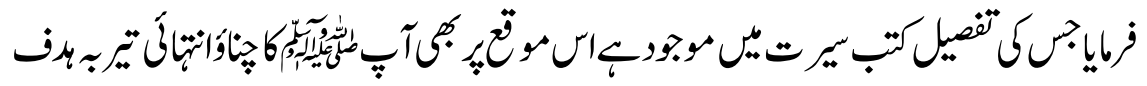

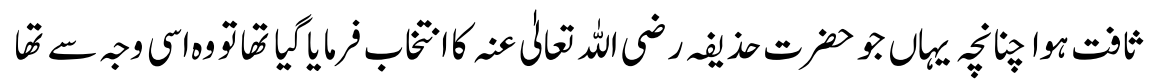

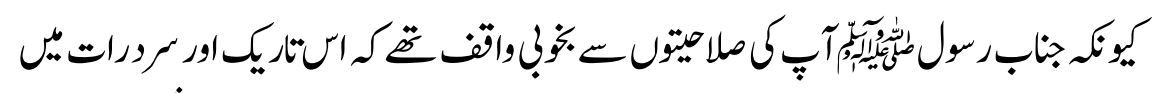

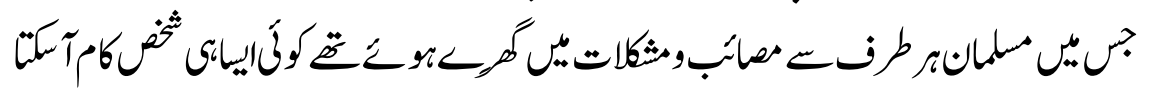

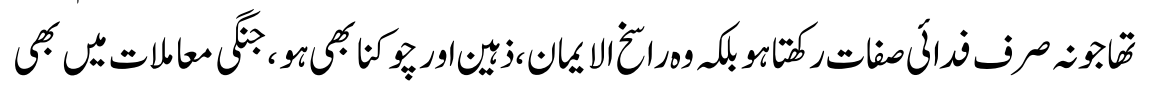




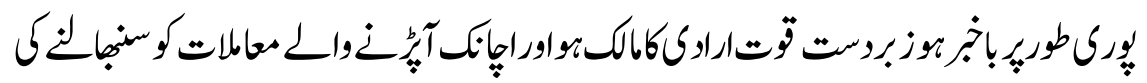

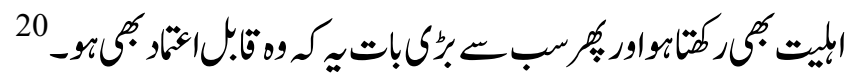

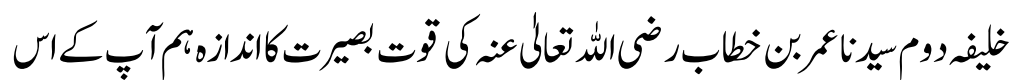

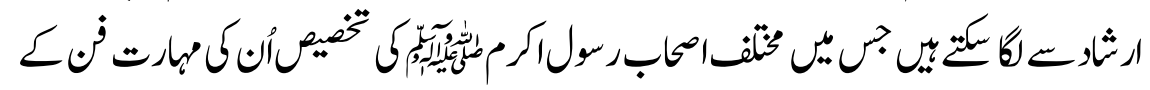

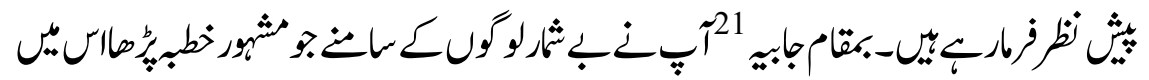

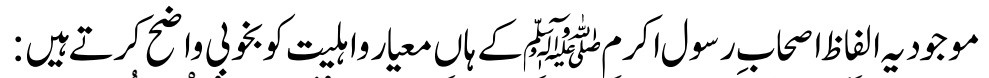

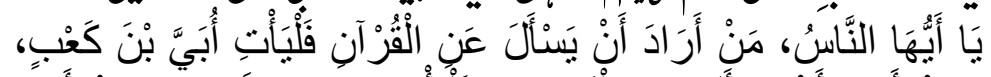

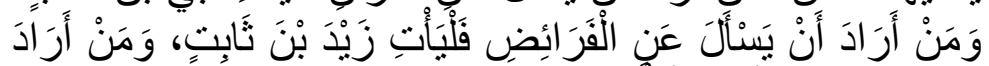

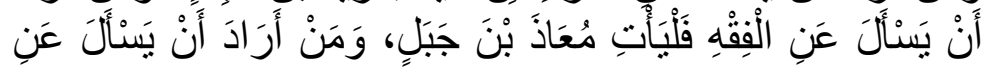

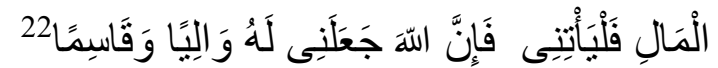

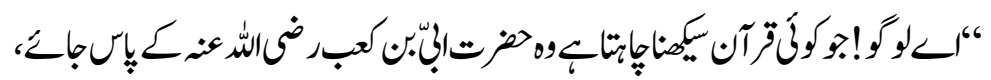

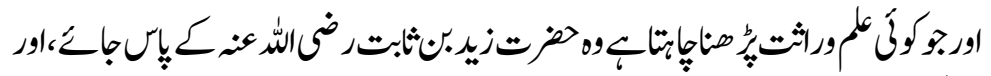

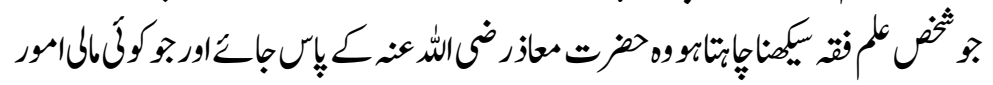

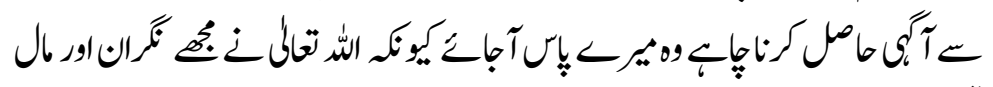
"تيم كرنوالابناياب"

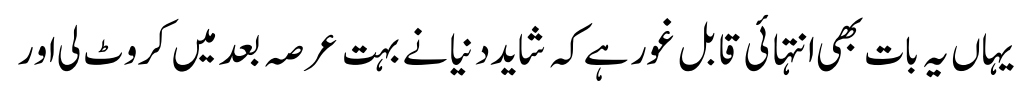

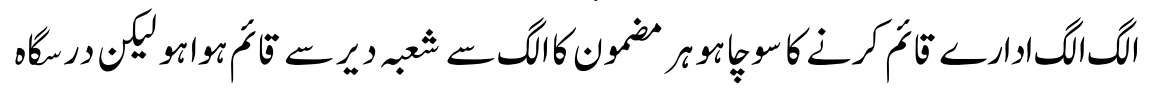

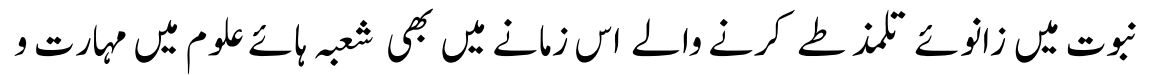

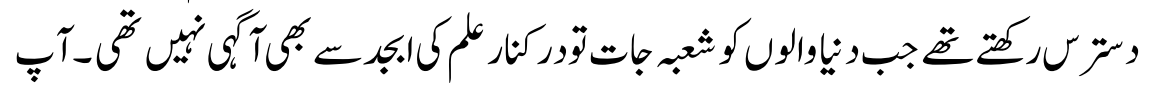

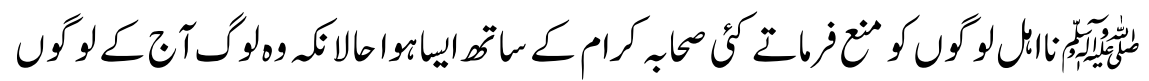

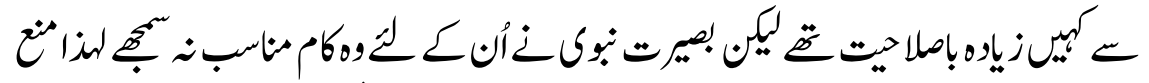

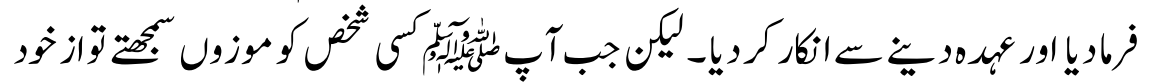

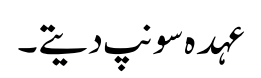




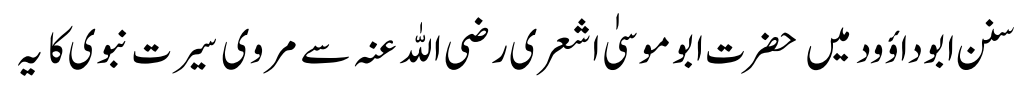

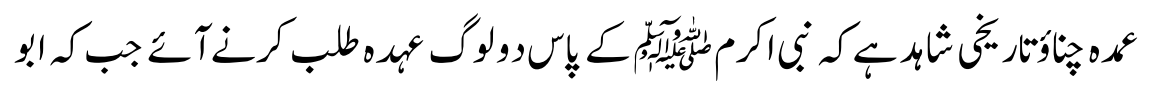

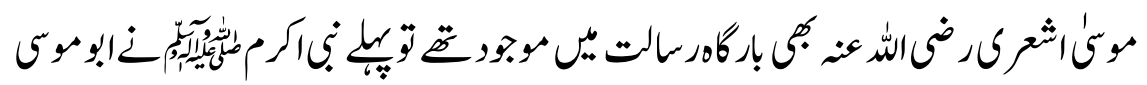

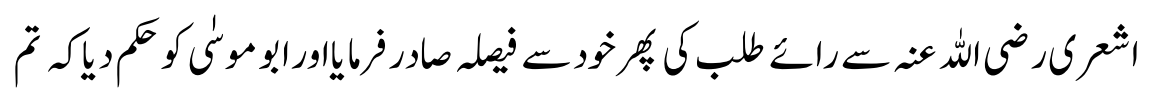

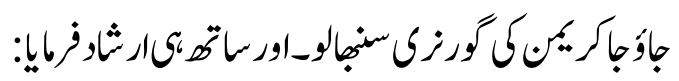

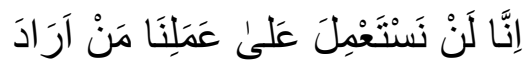

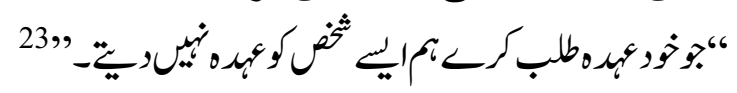

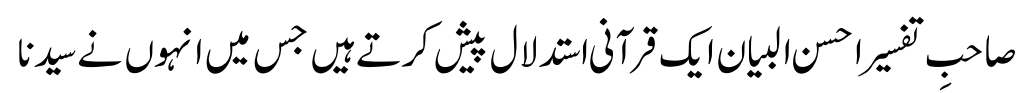

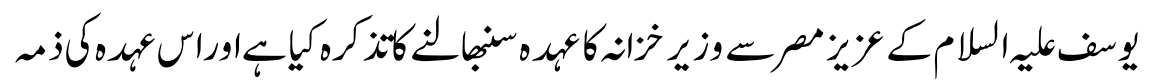

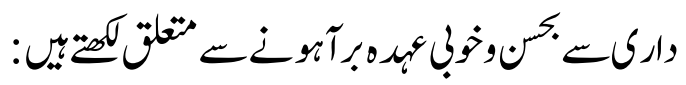

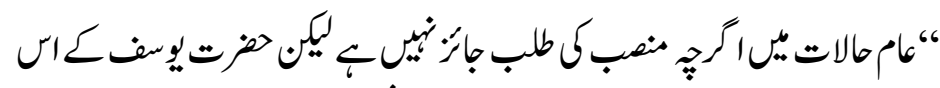

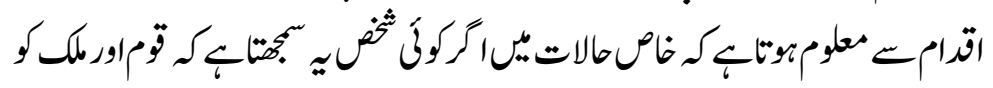

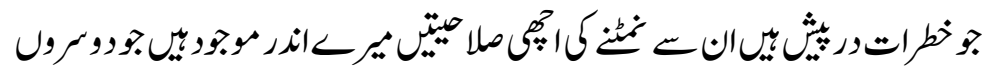

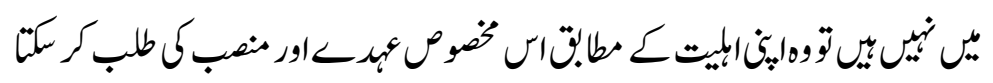
$-"$

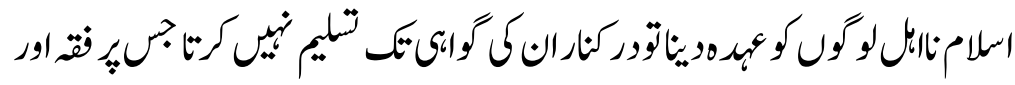

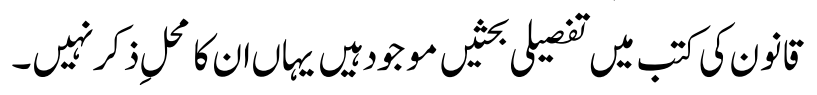

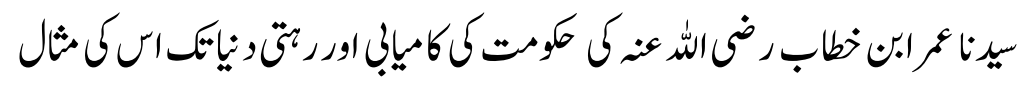

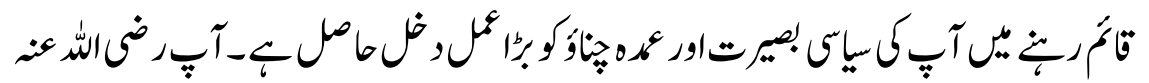

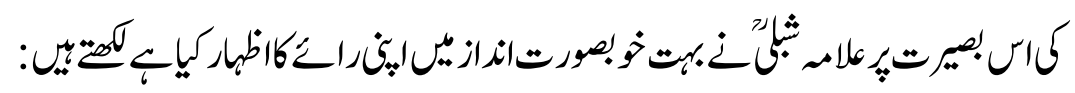




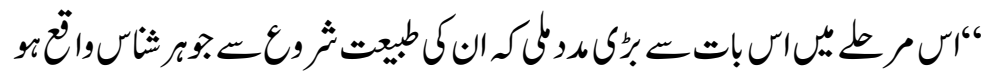

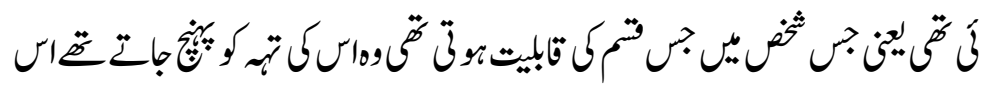

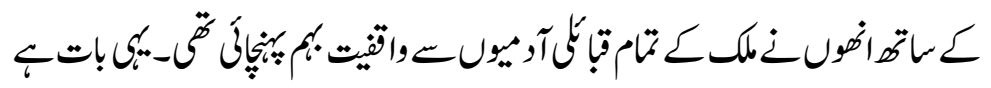

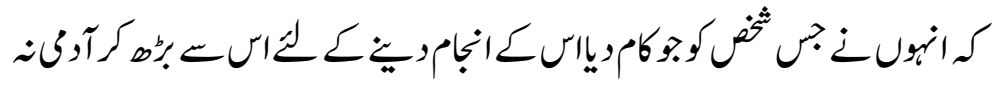
"24

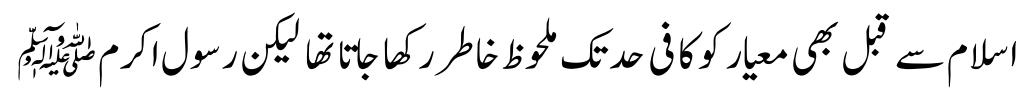

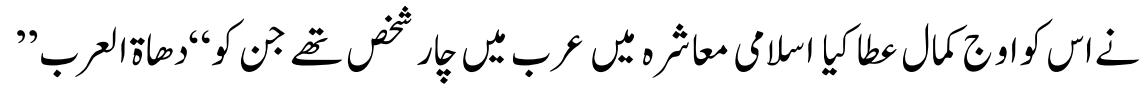

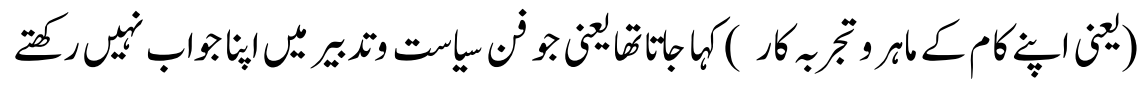

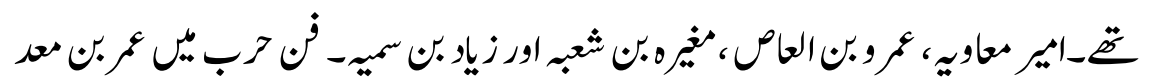

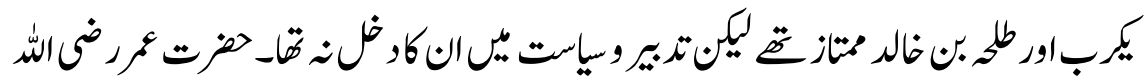

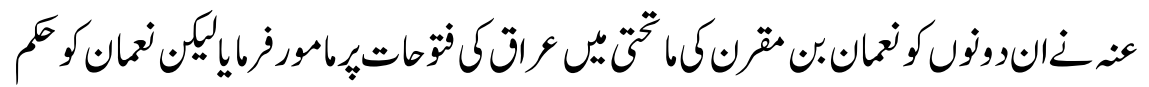

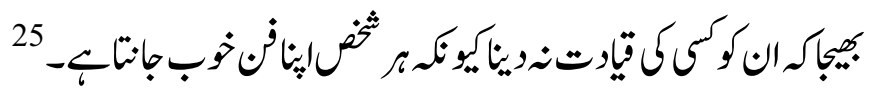

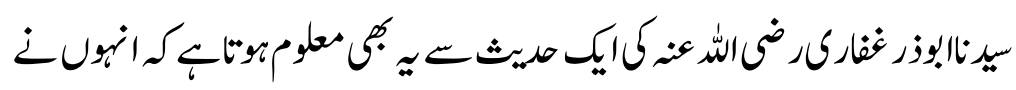

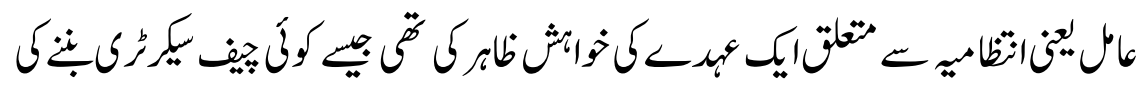

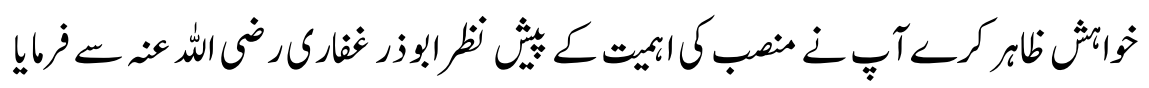

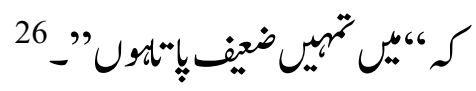

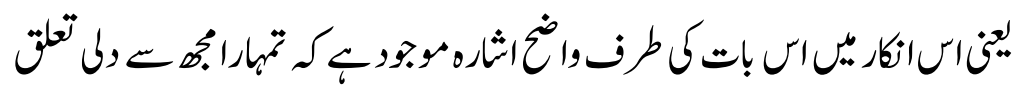

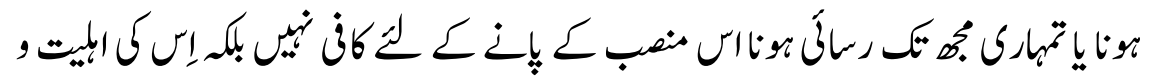

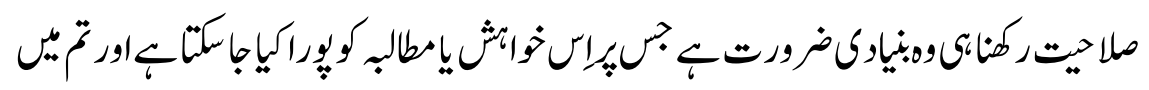

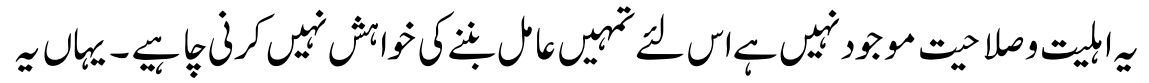




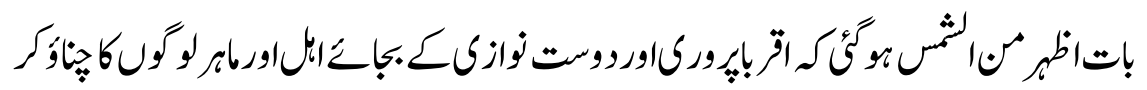

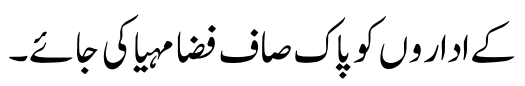

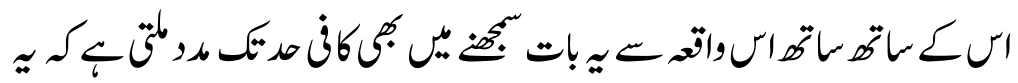

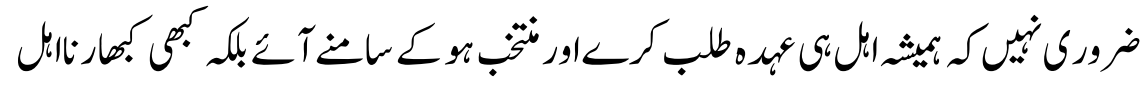

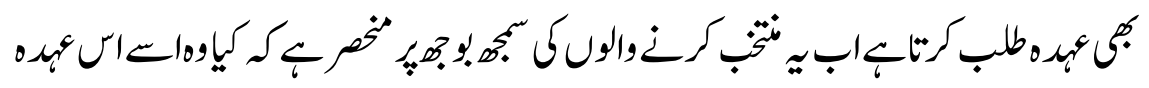

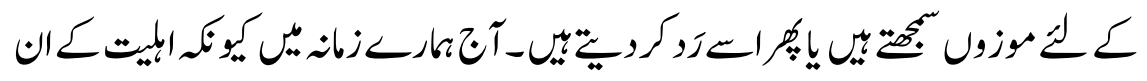

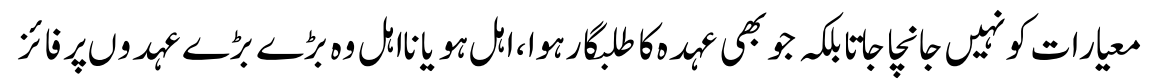

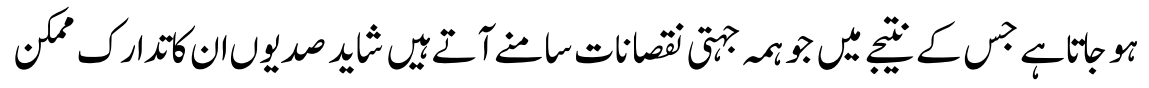
"بs

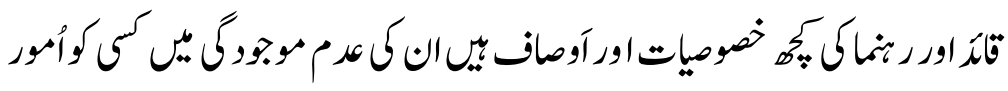

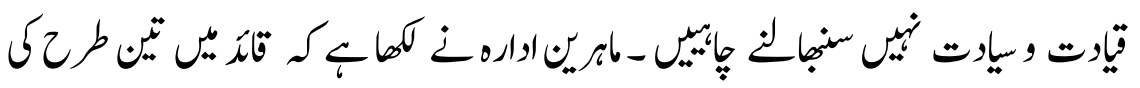

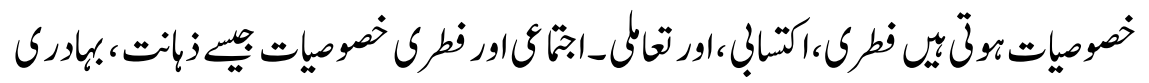

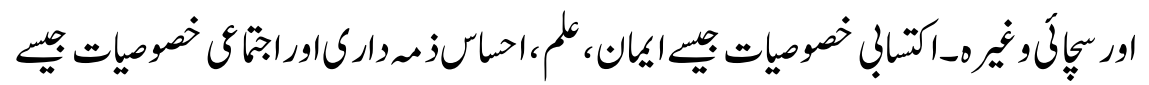

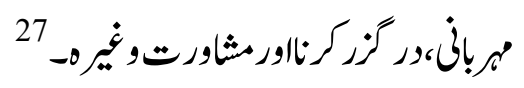

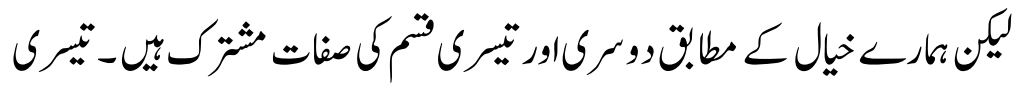

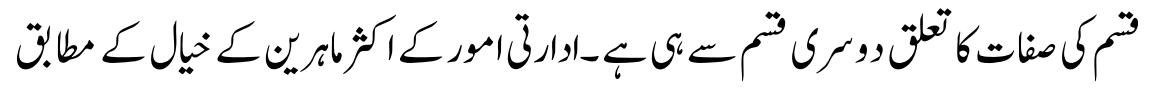

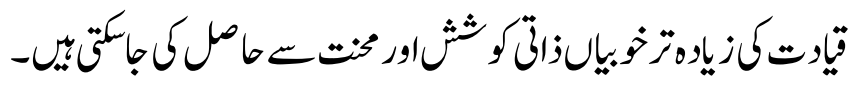

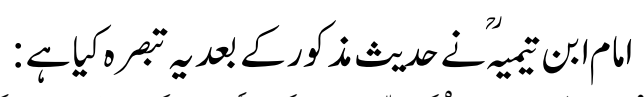

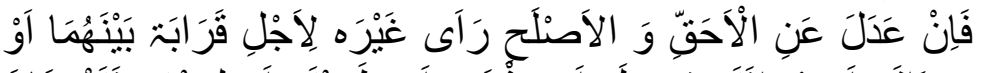

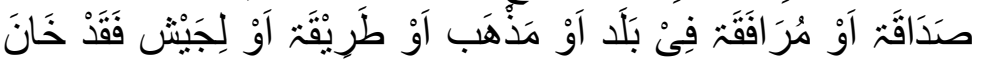

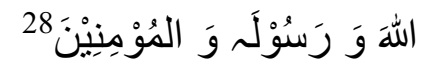




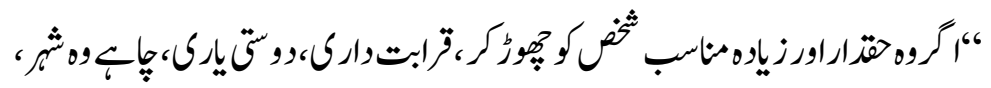

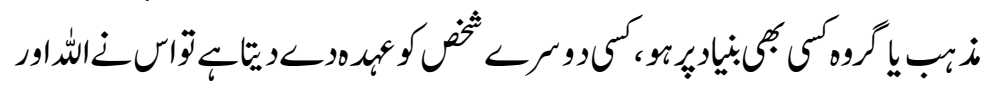

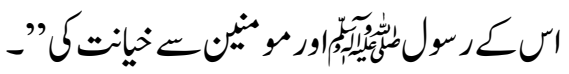

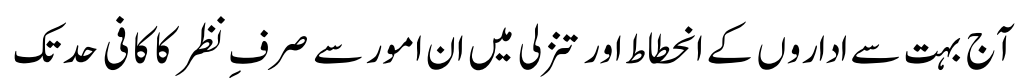

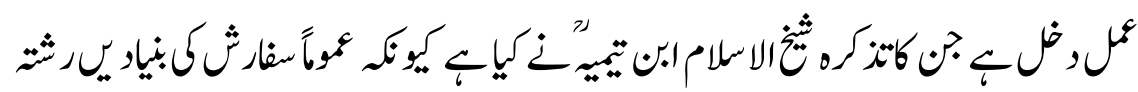

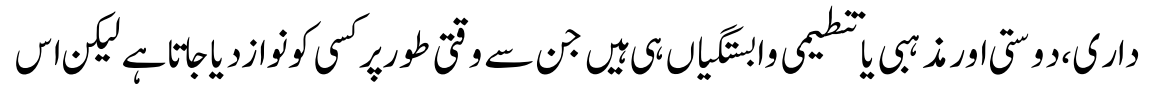

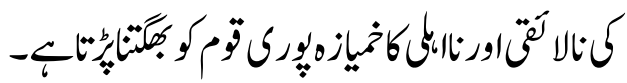

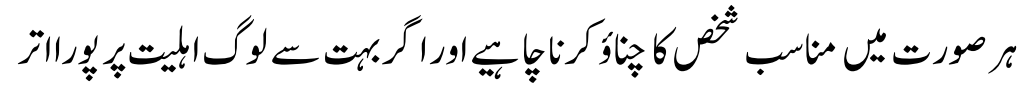

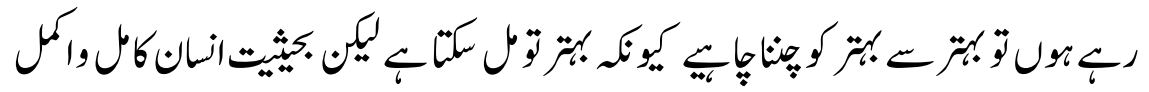

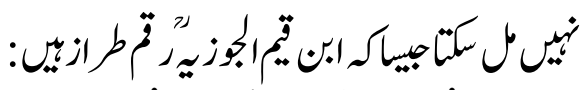

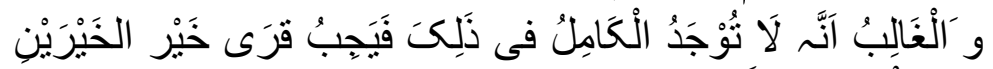

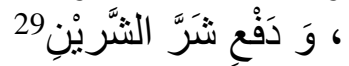

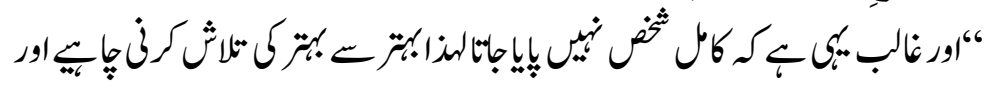
نامناسب كبيكاجِ

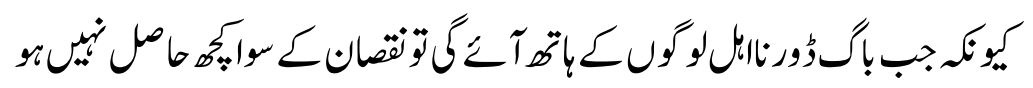

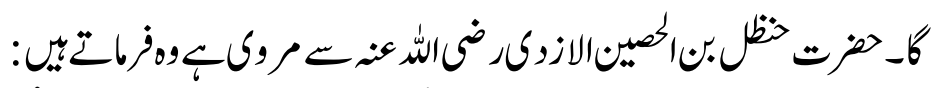

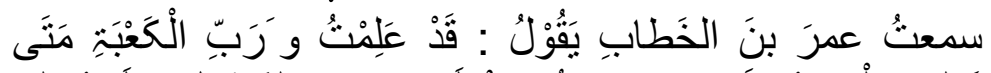

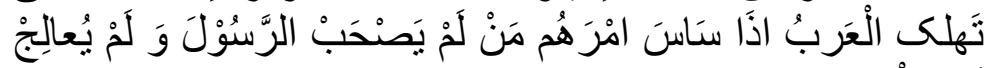

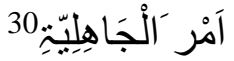

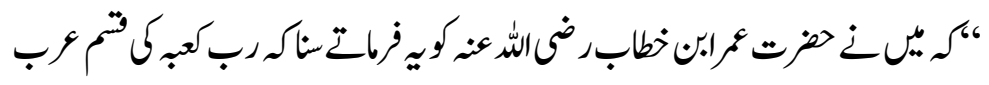

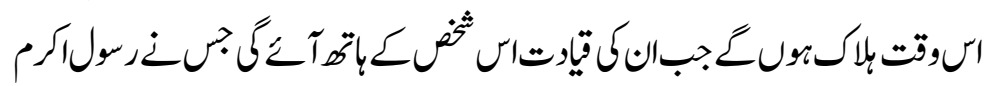

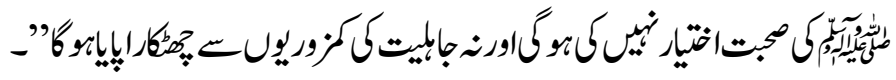




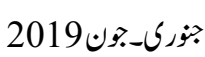

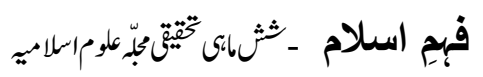

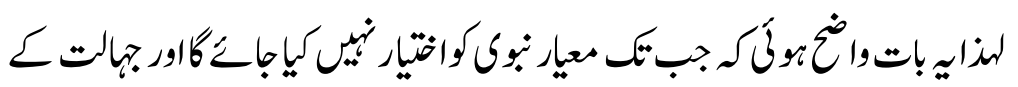

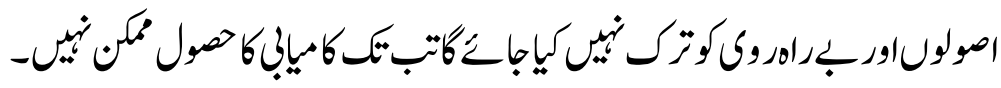

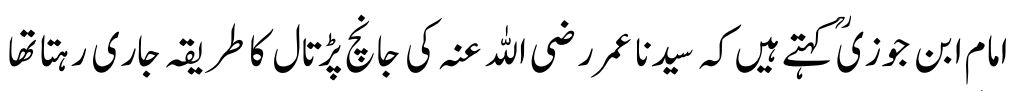

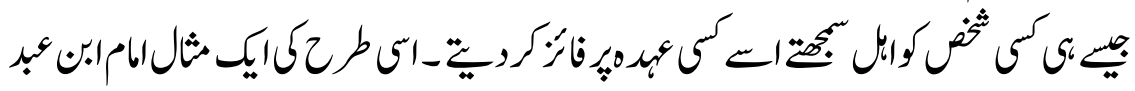

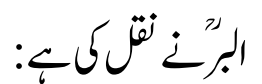

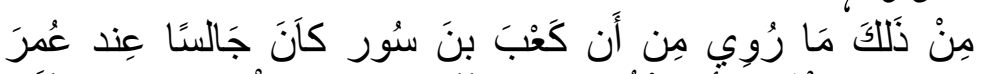

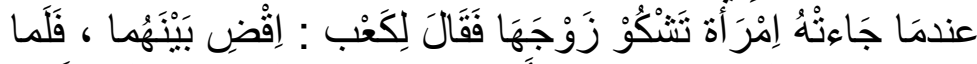

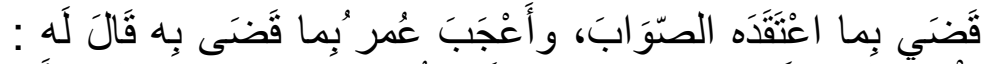

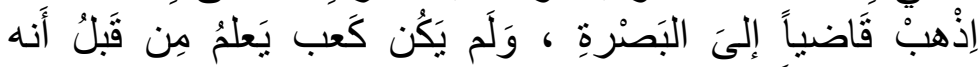

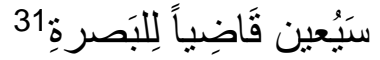

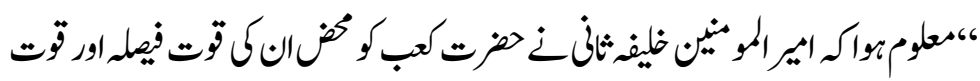

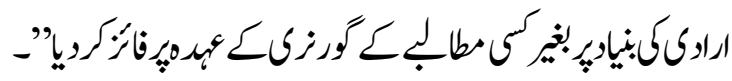

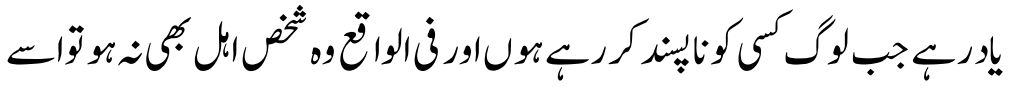

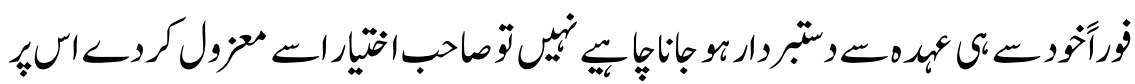

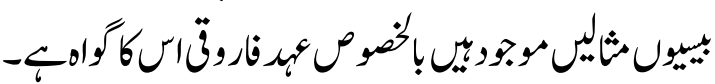

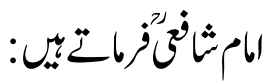

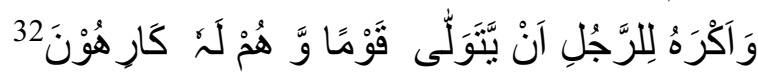

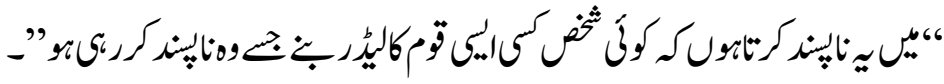

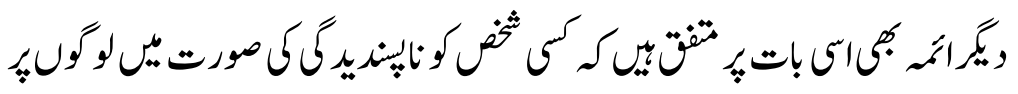

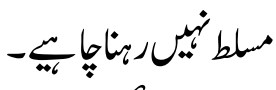

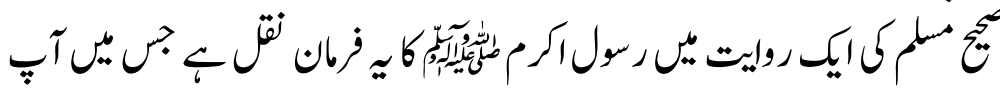

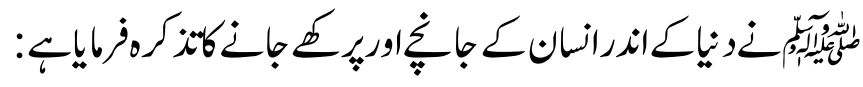

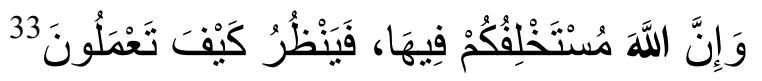

77 


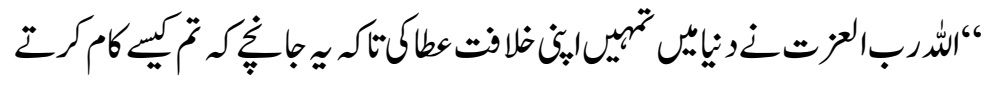

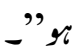

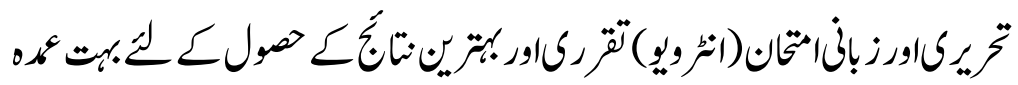

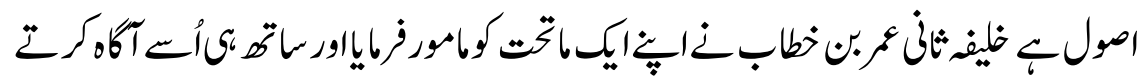

r

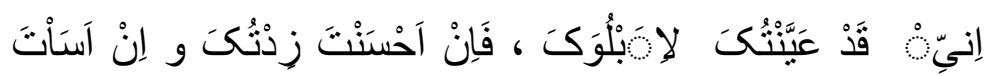

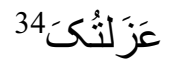

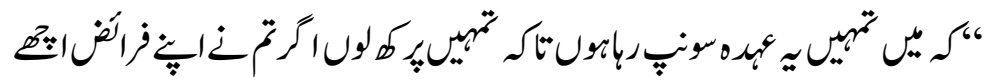

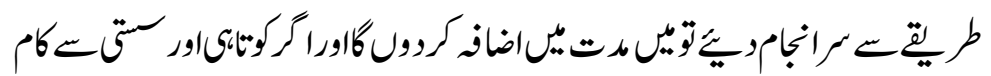

$$
\text { ليإت" تهي مקزول كروبه" }
$$

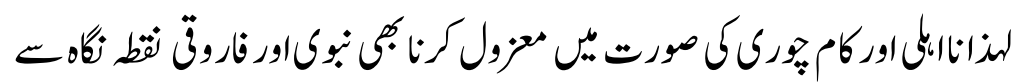

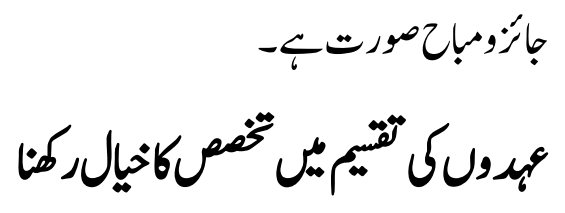

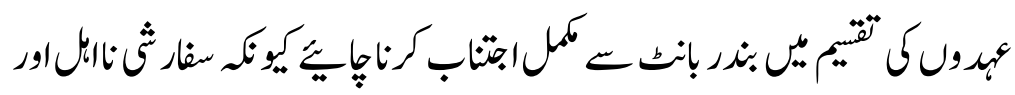

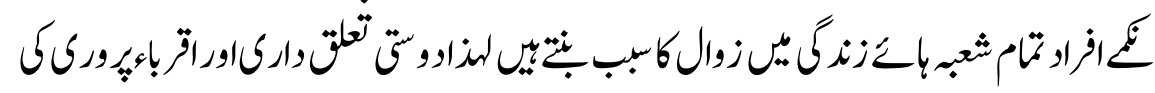

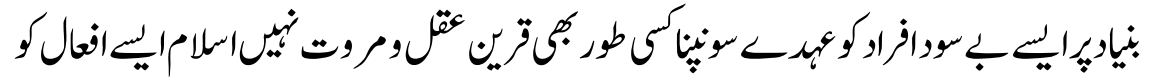

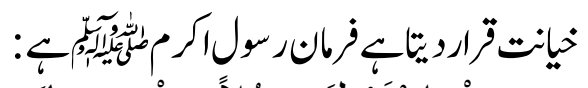

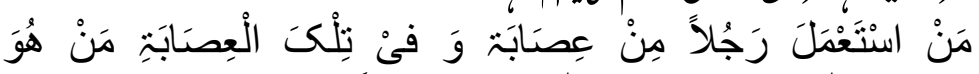

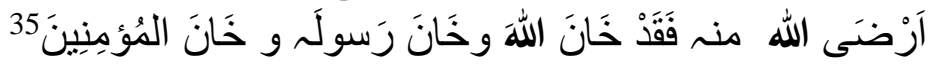

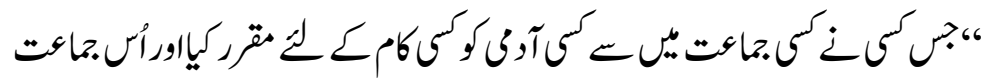

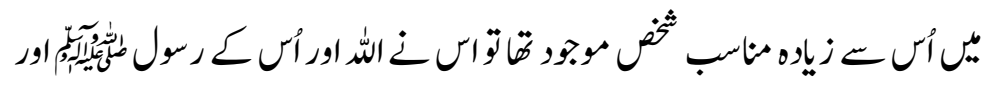

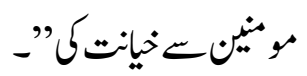


جزرك-جون2019

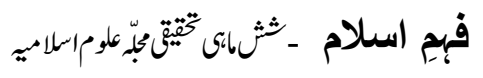

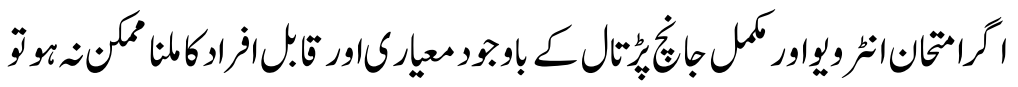

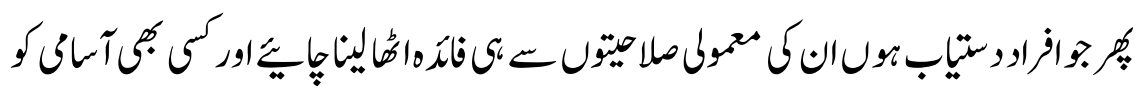

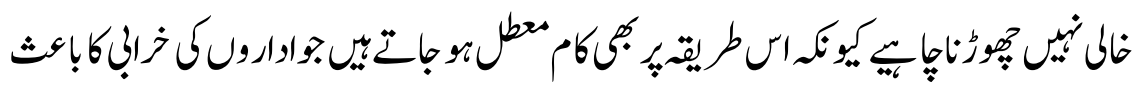

ب.

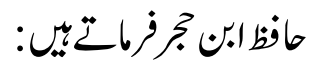

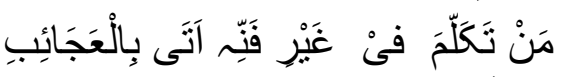

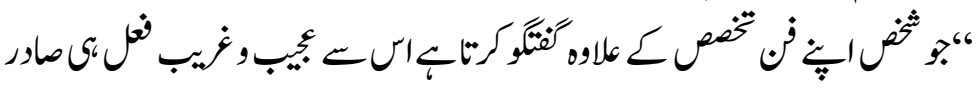

متحبي"

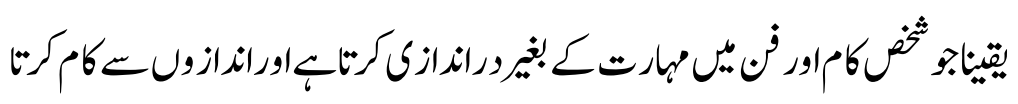

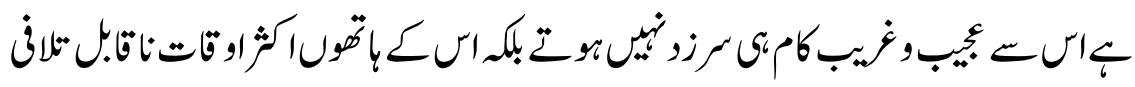

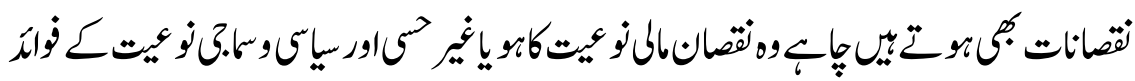

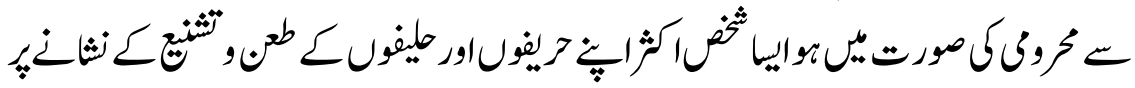

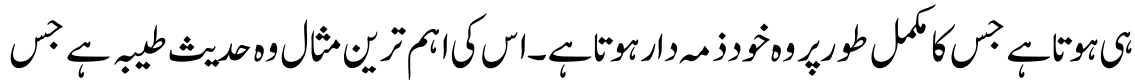

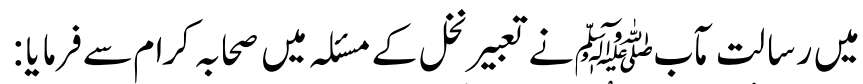

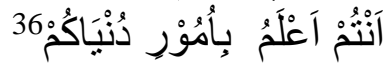

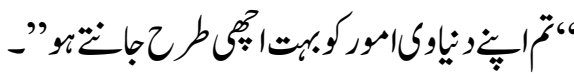

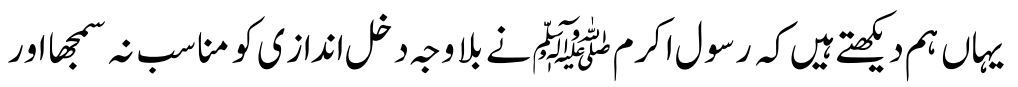

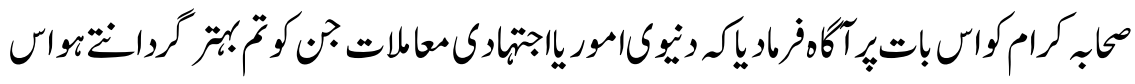

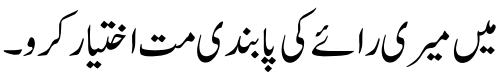

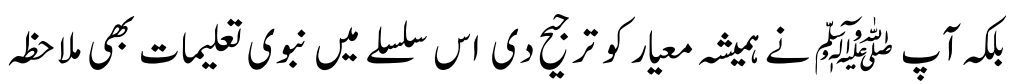

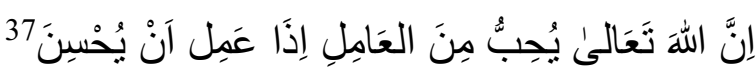

79 


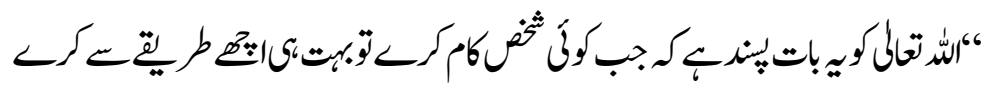

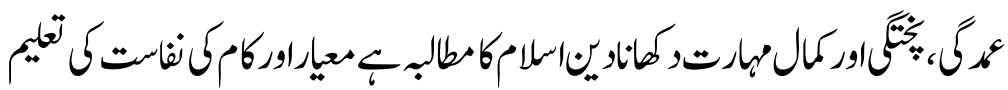

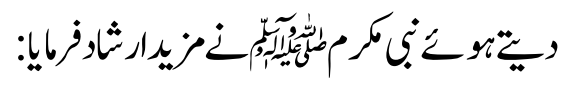

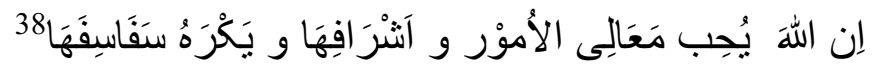

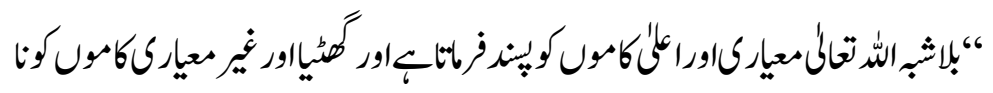

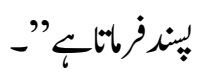

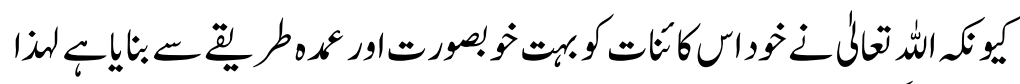

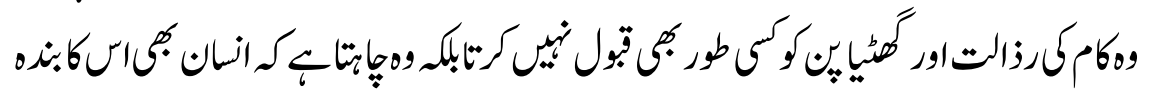

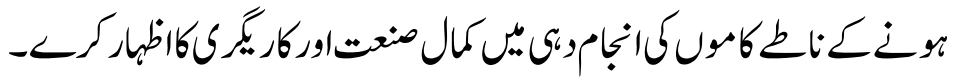

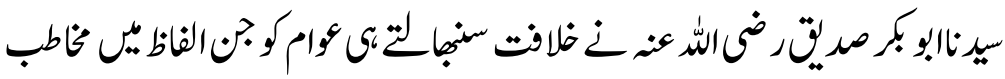

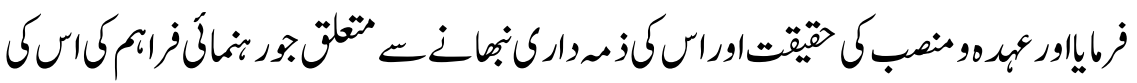

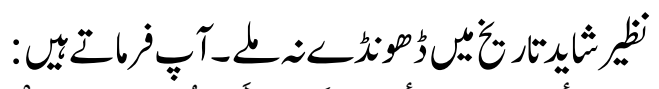

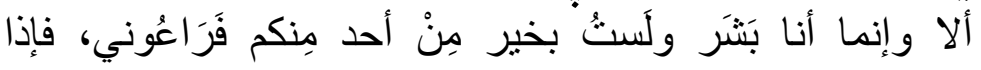

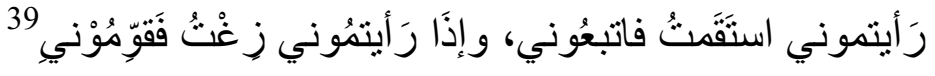

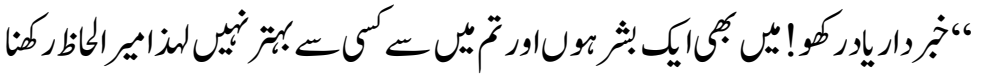

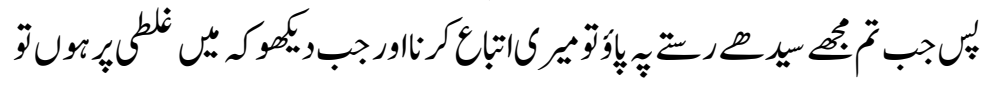

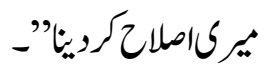

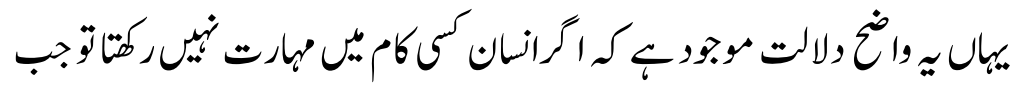

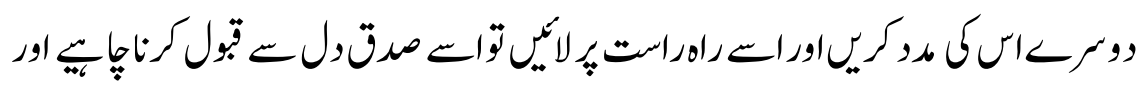

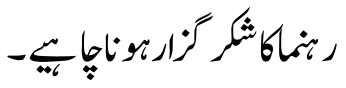




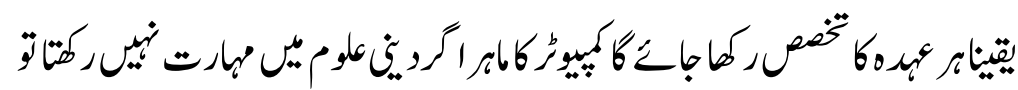

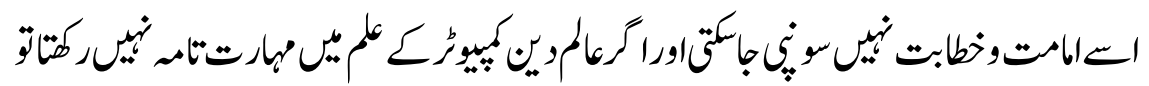

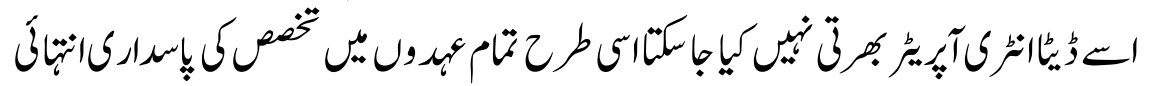

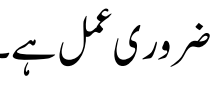

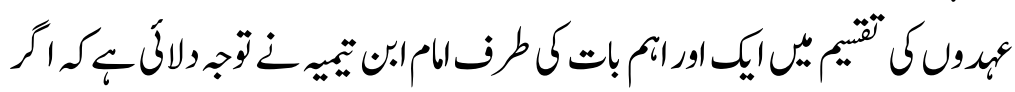

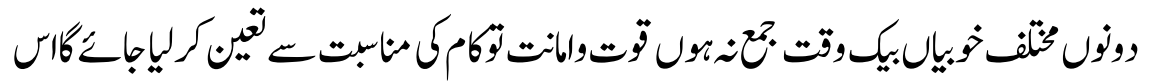

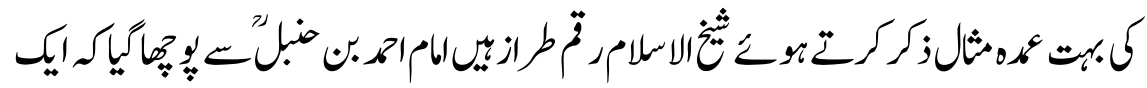

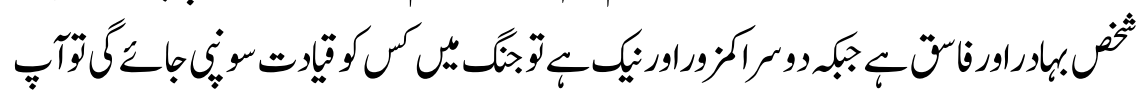

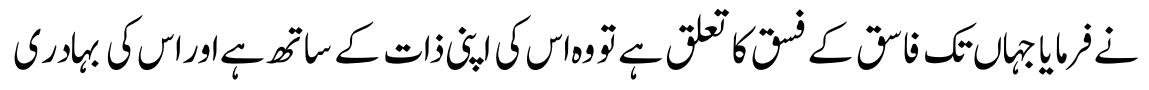

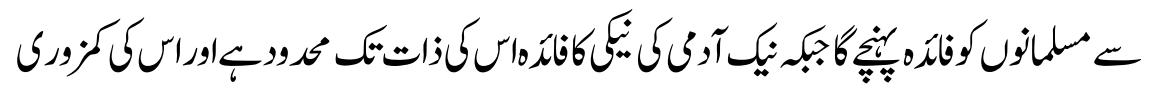

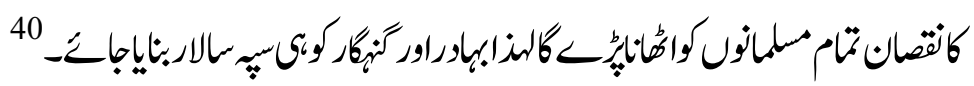

\section{اسلامكانظميزمدوارى}

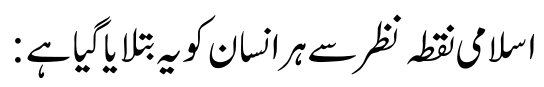

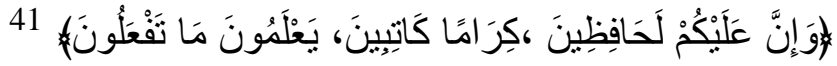

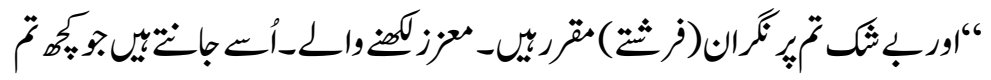

$$
\text { كرتبو" }
$$

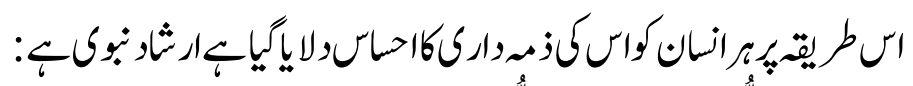

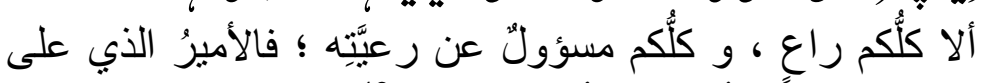

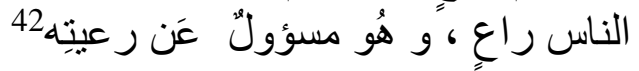

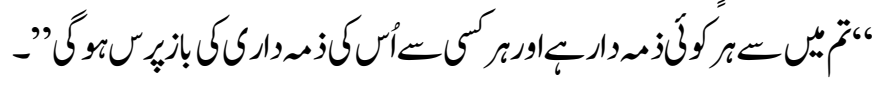




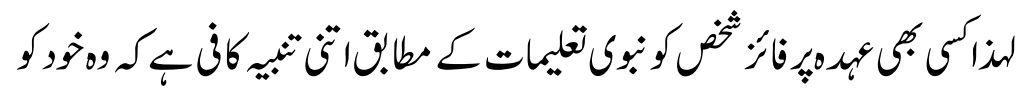

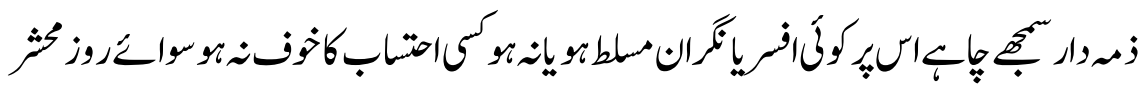

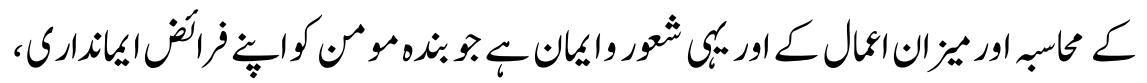

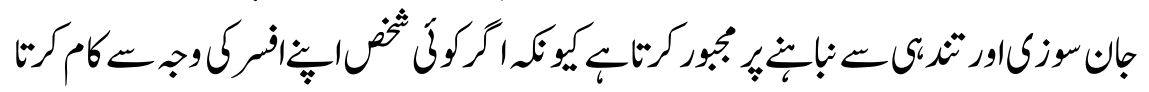

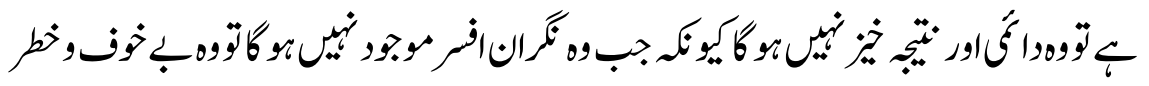

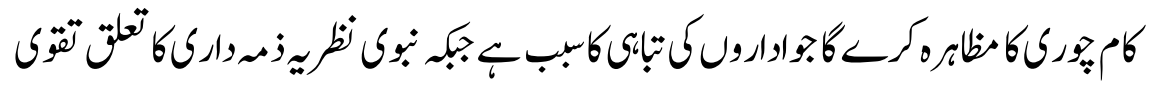

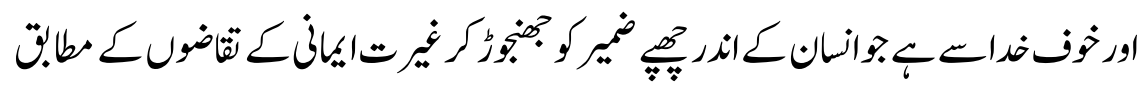

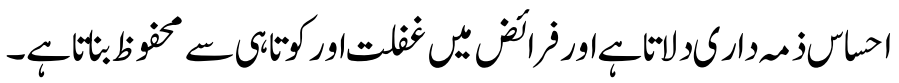

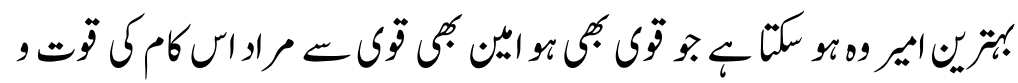

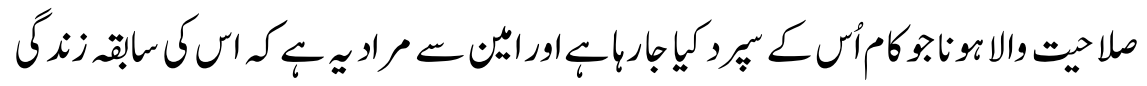

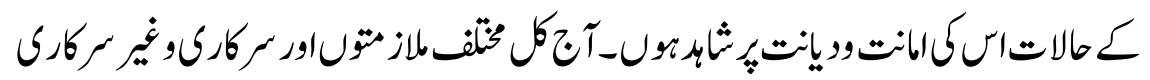

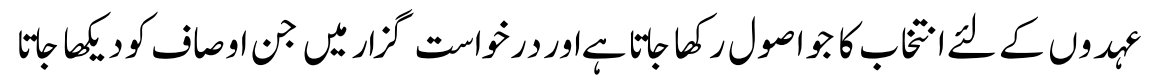

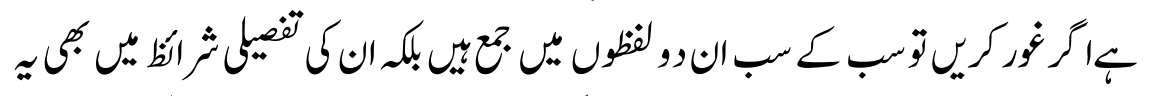

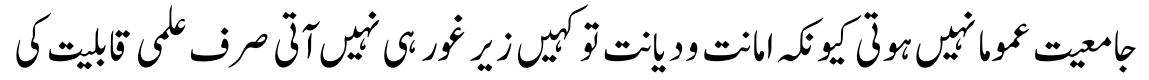

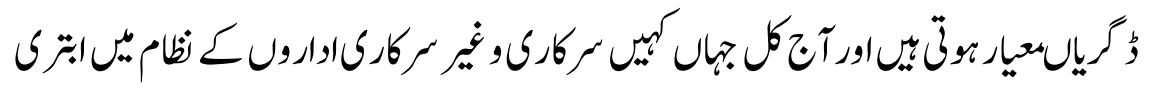

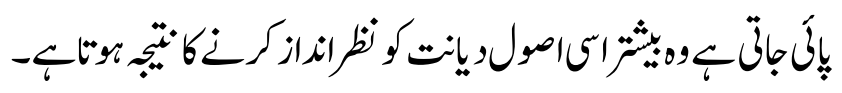

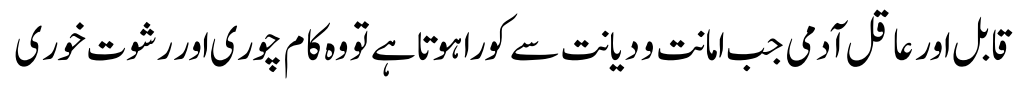

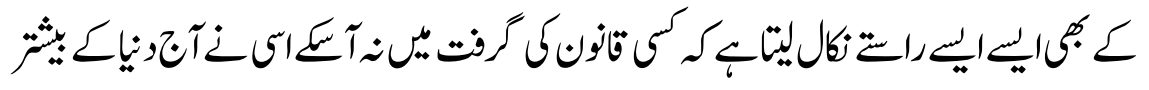

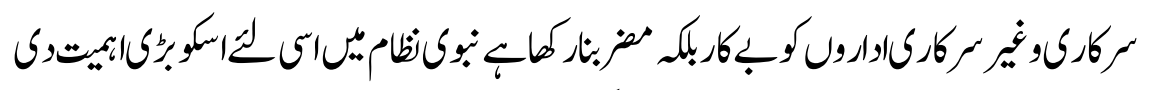

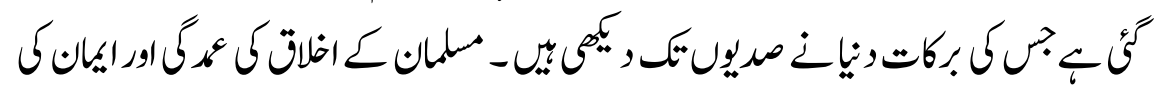

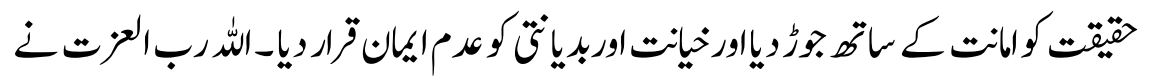

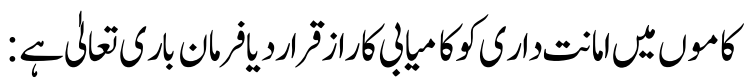




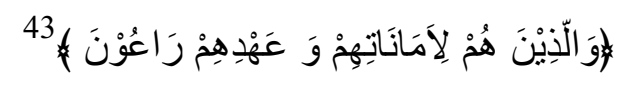

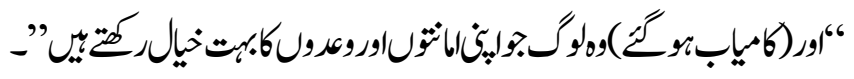

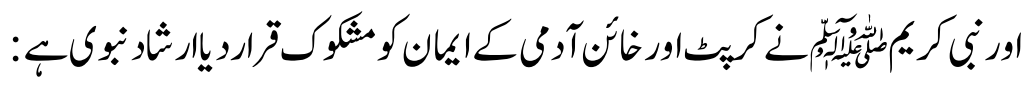

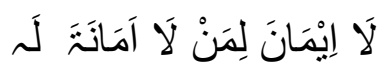

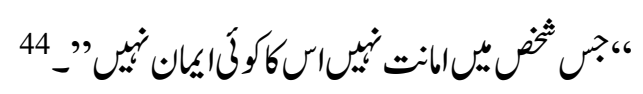

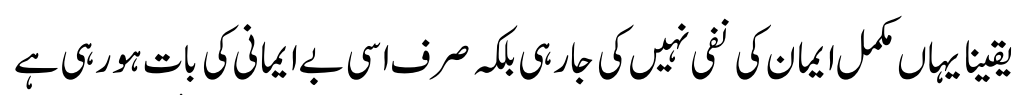

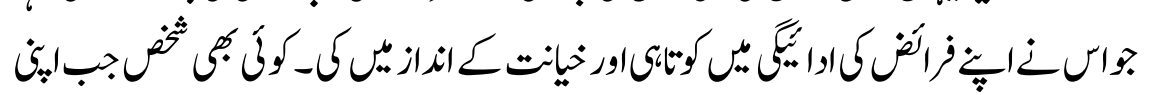

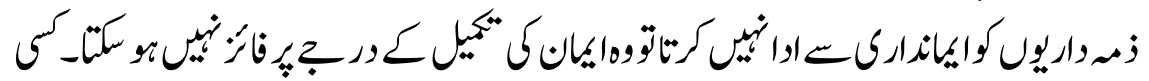

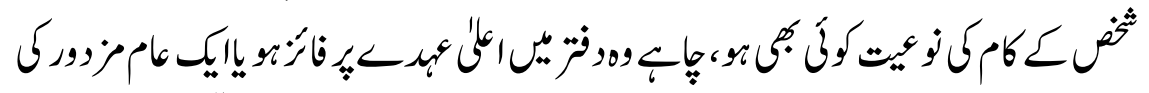

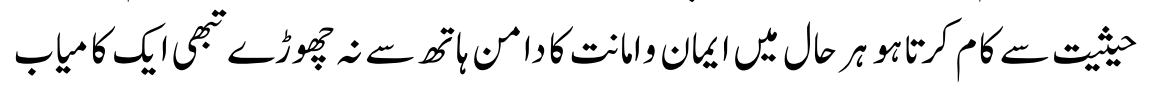

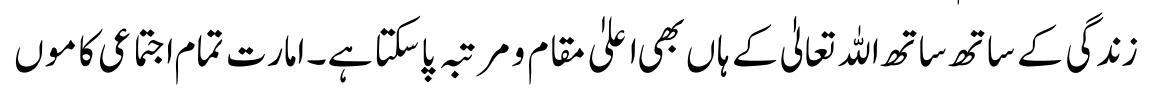

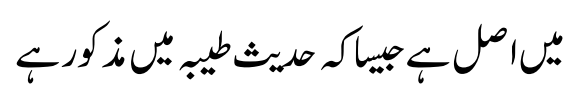

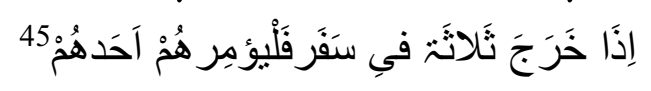

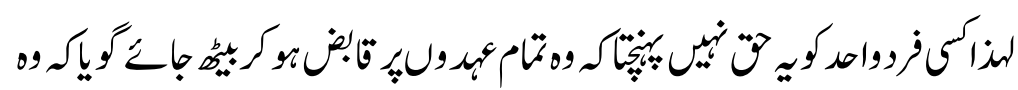

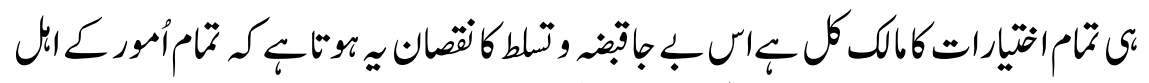

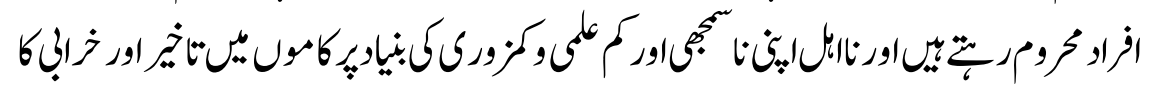

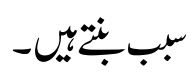

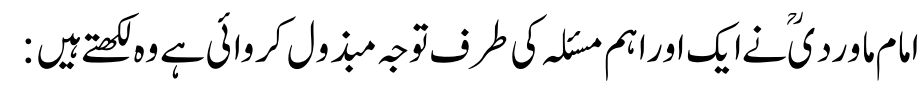

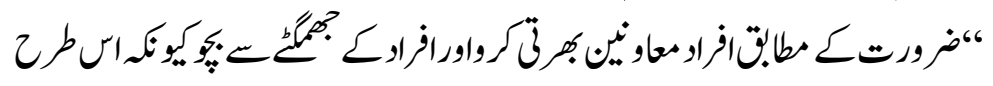

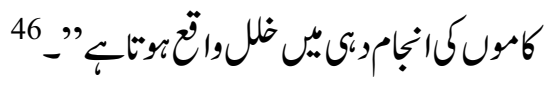

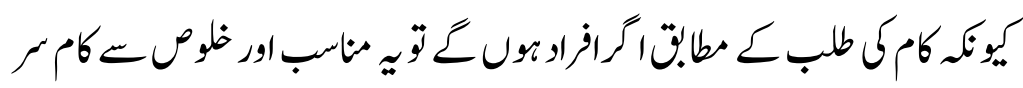

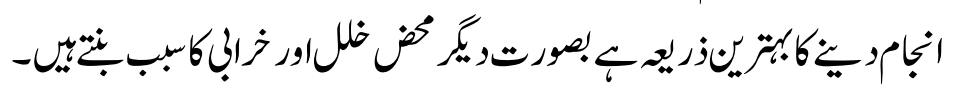




\section{منصبكن تخثناور زابا}

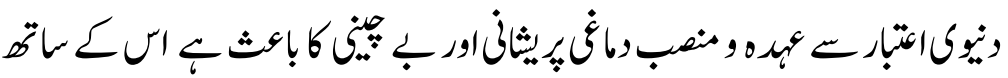

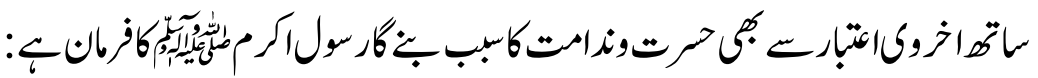

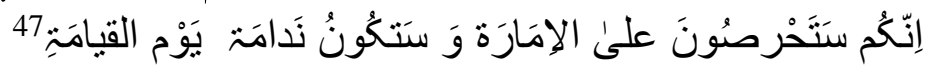

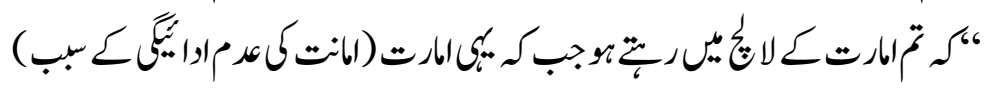

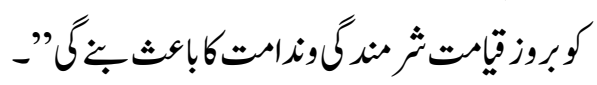

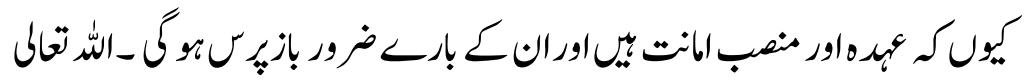

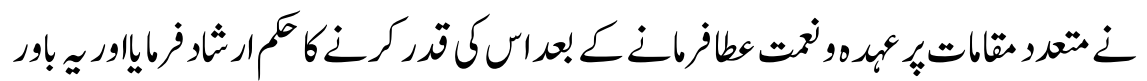

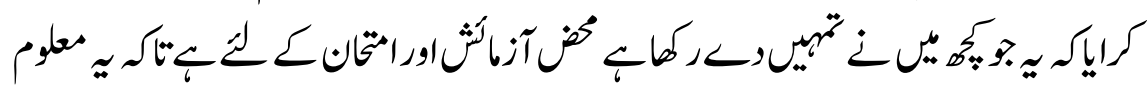

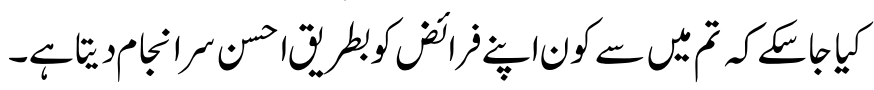

ثتيج.كث

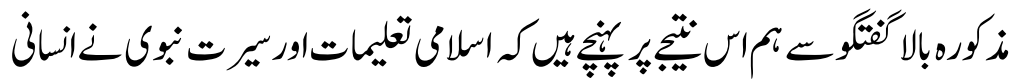

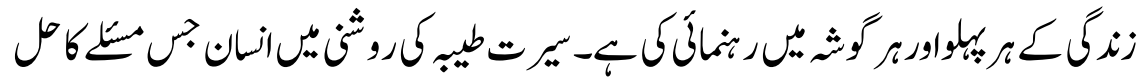

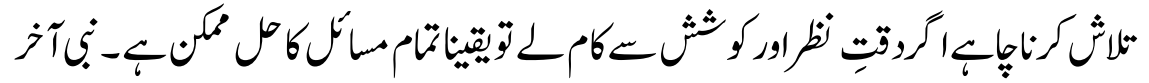

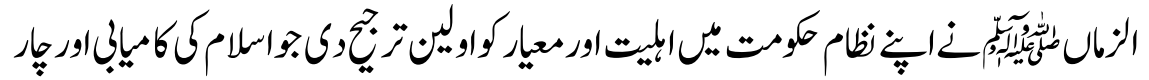

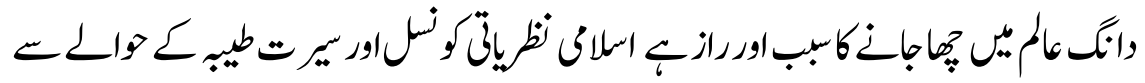

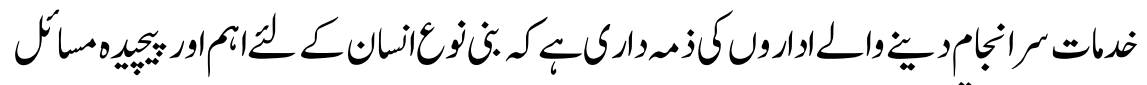

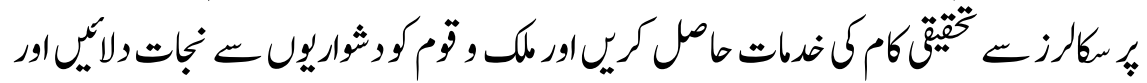

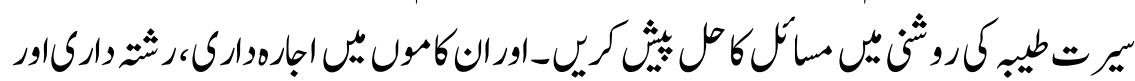

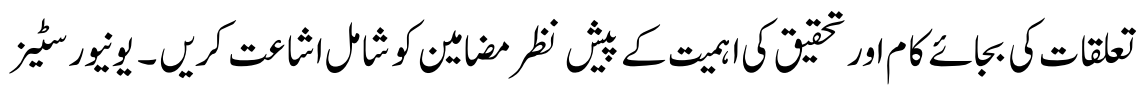

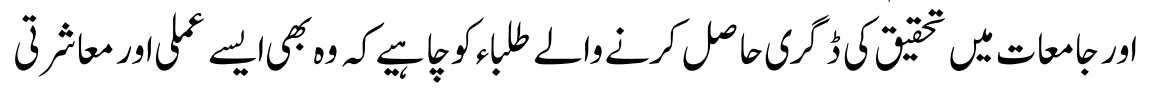




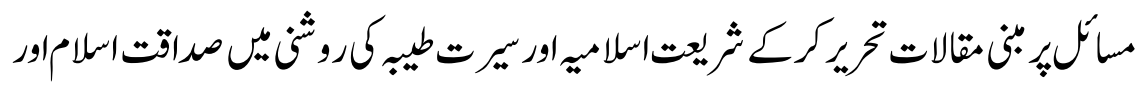

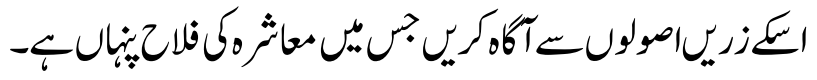

\section{مصاورومران}

$$
1
$$

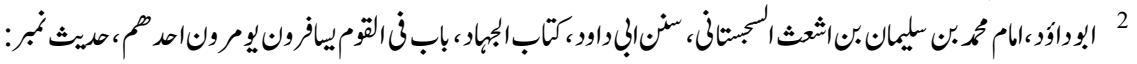

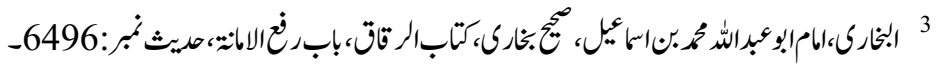

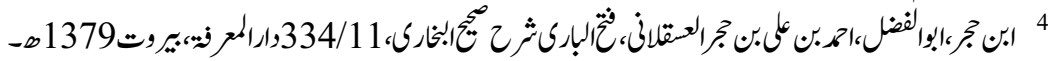

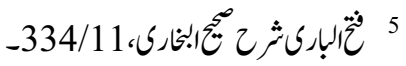

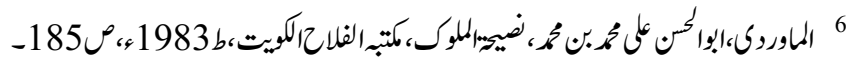

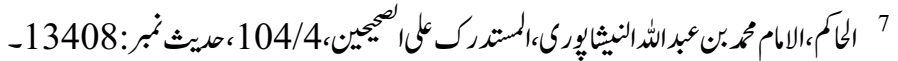

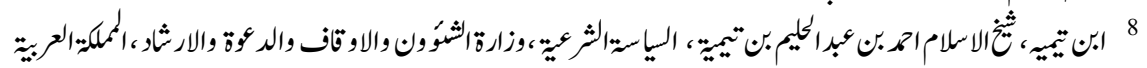

$$
\text { السعوريتص: }
$$

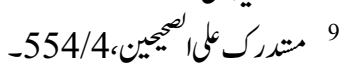

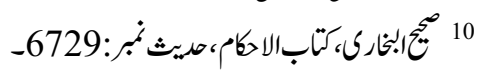

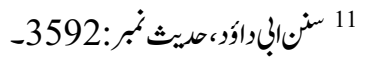
12

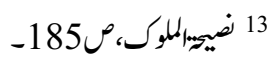

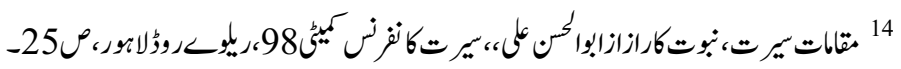

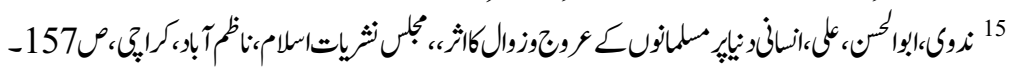
16 سورة/القم/ 16

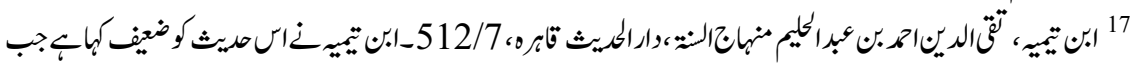

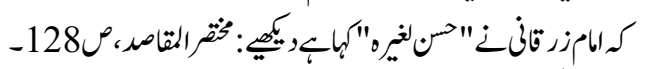

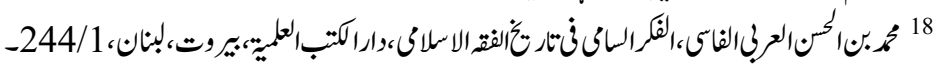

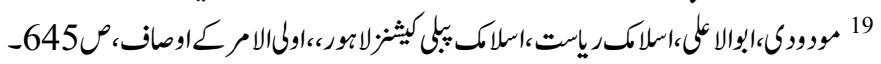

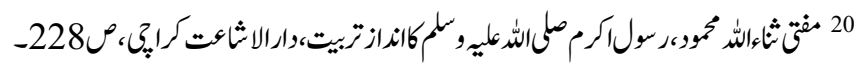

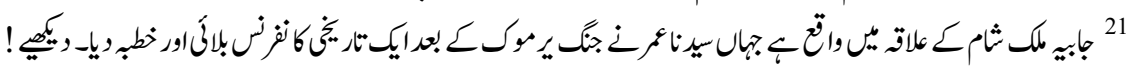

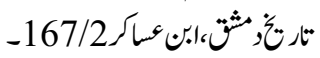




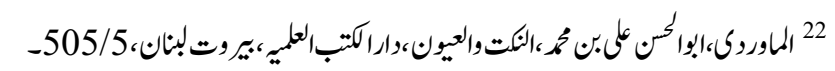

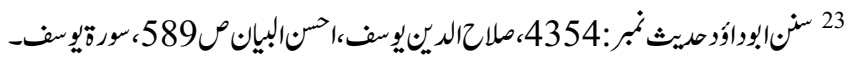

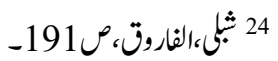
25

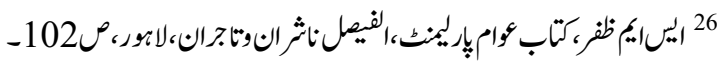

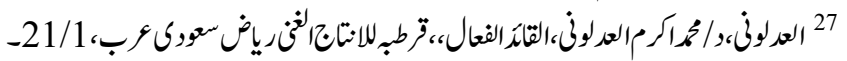
28

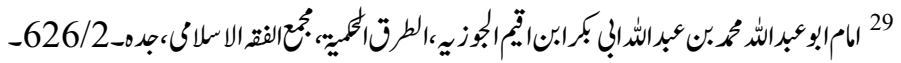

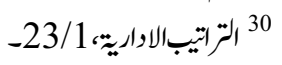

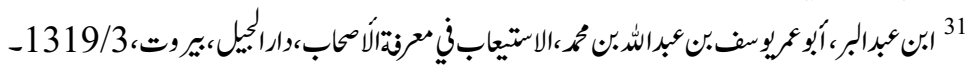

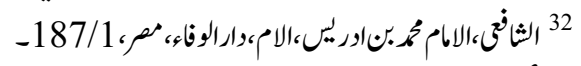

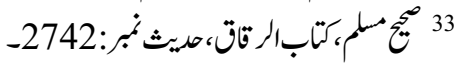

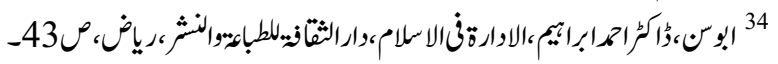

$$
35
$$

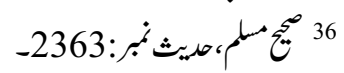

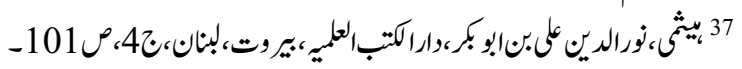

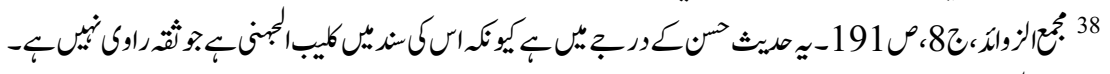

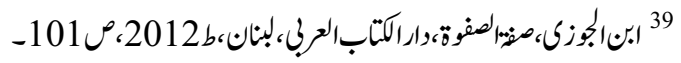

$$
40
$$

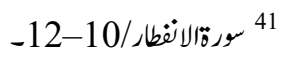

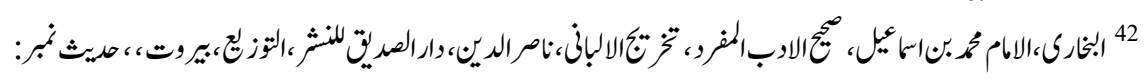

$-6188$

$$
43
$$

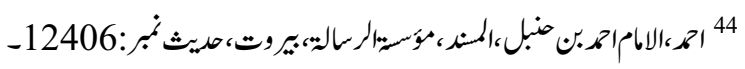
45 46 نيميرالموك، 454

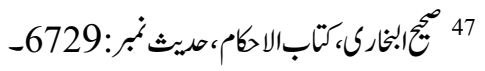

